University of Nebraska - Lincoln

DigitalCommons@University of Nebraska - Lincoln

9-9-2002

\title{
Financial Disclosure and Speculative Bubbles: An International Test of Asymmetry
}

Benjamas Jirasakuldech

University of the Pacific, Stockton, CA, b.jirasakuldech@sru.edu

Thomas S. Zorn

University of Nebraska-Lincoln, tzorn1@unl.edu

John Geppert

University of Nebraska-Lincoln, jgeppert1@unl.edu

Follow this and additional works at: https://digitalcommons.unl.edu/financefacpub

Part of the Finance and Financial Management Commons

Jirasakuldech, Benjamas; Zorn, Thomas S.; and Geppert, John, "Financial Disclosure and Speculative Bubbles: An International Test of Asymmetry" (2002). Finance Department Faculty Publications. 10. https://digitalcommons.unl.edu/financefacpub/10

This Article is brought to you for free and open access by the Finance Department at DigitalCommons@University of Nebraska - Lincoln. It has been accepted for inclusion in Finance Department Faculty Publications by an authorized administrator of DigitalCommons@University of Nebraska - Lincoln. 
Financial Disclosure and Speculative Bubbles: An International Test of Asymmetry

\author{
Benjamas Jirasakuldech, CFA \\ Assistant Professor of Finance \\ University of the Pacific \\ Eberhardt School of Business \\ Weber Hall 201A \\ 3601 Pacific Avenue \\ Stockton, CA 95211 \\ Tel: 209-946-2176 \\ Fax: 209-946-2586 \\ bjirasak@uop.edu
}

Thomas S. Zorn

George B. Cook College Professor of Finance

and The J.D. Edwards College Professor

University of Nebraska-Lincoln

CBA 231

Lincoln, NE 68588-0490

Tel: 402-472-6049

Fax: 402-472-5140

tzorn1@unl.edu

\author{
John M. Geppert \\ Associate Professor of Finance \\ University of Nebraska-Lincoln \\ CBA 229 \\ Lincoln, NE 68588-0490
}

Tel: 402-472-3370

Fax: 402-472-5140

igeppert1@unl.edu

September 9, 2002

We also wish to thank Manferd Peterson, Kathy Farrell, Richard DeFusco, and Mary McGarvey for helpful comments. Benjamin Kim provided some of the data and John Geppert provided assistance with programming.

Published online in Social Science Research Network @ http://papers.ssrn.com/sol3/papers.cfm?abstract_id=330080 


\title{
Financial Disclosure and Speculative Bubbles: An International Test of Asymmetry
}

\begin{abstract}
$\underline{\text { Abstract }}$
This paper applies two tests of asymmetry to examine if the quality of a country's financial disclosure system affects the likelihood of speculative bubbles. We examine the hypothesis that stock prices of firms in countries with a low level of financial disclosure are more likely to experience bubbles. The countries, ranked in order of disclosure levels, are the United States, Canada, the United Kingdom, the Netherlands, France, Japan, Germany, and Switzerland (Saudagaran and Biddle (1992)). The findings based on the third-order Markov chain test suggest the presence of asymmetry in dollardenominated quarterly real returns of Japan, a country with a relatively low level of disclosure. The asymmetric pattern indicates the non-random walk return pattern of Japan. The results based on the time reversibility test indicate that monthly real returns in both dollar-denominated and local currencies of Germany increase slower than they decrease. Such "slow-up and fast-down" dynamic is consistent with the presence of a bubble.
\end{abstract}




\section{Financial Disclosure and Speculative Bubbles: An International Test of Asymmetry}

\section{Introduction}

The importance of financial reporting, as reflected in accounting standards, has been controversial among academicians. What role, if any, financial disclosure has in determining security prices is not clear. The strong form of the efficient market hypothesis implies that such information is totally redundant. Rational expectations theory predicts that investors always have unbiased forecasts of future values. Excluding the very special case of rational expectations bubbles, speculative bubbles, if they exist, clearly are incompatible with rational expectations. The existence of speculative bubbles is also controversial. It is nevertheless plausible to suppose that more stringent reporting requirements can more closely align market values with fundamentals.

The term speculative bubble is used in the general sense that high returns by themselves cause investors to bid prices higher, i.e., speculative bubbles are caused by past price performance rather than underlying fundamentals. Disappointments are inevitable. A speculative bubble; therefore, occur when upswings are gradual and downswings are rapid; a return pattern that is asymmetric or non-linear.

Zeff (1972) reported that poor accounting and reporting practices were the cause of the October 1929 collapse. MacDonald (1998) pointed out that the collapse of the Thai economy in 1997 was due to the lack of transparency. Greenspan (1998) further suggested that improvement in transparency is necessary to prevent future financial crisis. Using two different methodologies, this paper examines whether the quality of a country’s financial disclosure system has any effect on the likelihood of speculative 
bubbles. That is, are stock markets in countries with more lax disclosure more prone to have speculative bubbles? The quality of a country's accounting or financial information disclosure system in this study refers to the quantity and intensity of information reported in meeting the statutory requirements, exchange filing and listing requirements, and capital market expectation. The major stock markets in eight countries are examined. The eight countries are ranked from the highest to the lowest in terms of disclosure. The country's disclosure level rankings (DLR) are obtained from the study done by Saudagaran and Biddle — henceforth S\&B (1992). According to S\&B (1992), firms in the United States had the highest level of disclosure, followed in order by Canada, the United Kingdom, the Netherlands, France, Japan, Germany, and Switzerland.

A non-parametric Markov chain test developed by McQueen and Thorley (1991) and the time reversibility test developed by Ramsey and Rothman (1996) are used to test for the presence of nonlinearities or asymmetry in the return series of eight countries. In a market where the security price contains "price bubbles", which cause the market price to deviate significantly from the fundamental price, the security price is often characterized by a gradual increase in prices followed by a sharp drop. This particular pattern is consistent with an asymmetric structure where upswings and downswings exhibit a different pattern. That is to say, the existence of a bubble suggests a nonlinear return pattern.

A Markov chain is defined by letting state $1(0)$ represents positive (negative) returns. Symmetry requires that the probability of obtaining negative or positive returns be the same regardless of what happened in prior states. Specifically, if the return series have unequal transition probabilities then it is likely to find some form of asymmetry. In 
other words, if runs of positive returns persist longer than runs of negative returns, it indicates the likelihood of a bubble. If it can be empirically shown that the return patterns of stock prices in countries with relatively low disclosure levels are characterized by asymmetry, it is possible to argue that corporate fundamental information as disclosed in the financial reports affects the likelihood of bubbles.

A time reversibility test (TR) developed by Ramsey and Rothman (1988), (1996) suggests that if the covariance relationship of series going forward in time is the same as that going backward in time, the series is said to be time reversible or symmetric. On the other hand, if the structure is not the same, the series is defined as time irreversible or asymmetric. An asymmetric return pattern exhibiting a slow increase and quick decrease is consistent with speculative bubbles. If such patterns are found in the returns of countries with relatively low disclosure levels, it suggests that the quality of financial disclosure may explain the likelihood of bubbles.

Most of the bubble tests such as the variance bound tests and variance ratio tests assumed linearity of return patterns (Shiller (1981), LeRoy and Porter (1981) and Kleidon (1986)). The presence of a bubble; however indicates that the pattern is nonlinear or asymmetric. The asymmetry or non-linearity in any time series has been shown to have important implications for many theoretical finance models. Using a linear modeling technique to approximate a non-linear structure gives rise to two problems. First, the true nature of the underlying structure or relationship is likely to be misspecified (Peat and Stevenson (1996)). Second, any prediction and policy inferences from such models are also likely to be wrong. According to Neftci (1982), the prediction problem, as a result of using a linear model when the underlying nature is non-linear, will 
cause the "unpredictable component" or residual from the time series to contain excessive information. This will lead to the finding that estimated innovations are significant explanatory variables. As a consequence, linear modeling techniques are inadequate for modeling non-linear series. If security prices contain bubble components, which are nonlinear by nature, the linear model of fundamental value will not provide an accurate representation of the market prices. Therefore, these two nonparametric techniques, which accommodate the issue of non-linearity, will allow us to avoid the problem of using a linear model to estimate a non-linear structure.

Using a cross-country comparison, this paper provides empirical evidence on whether a more rigorous financial disclosure helps prevent the occurrence of a bubble. A second-order Markov chain shows strong evidence of symmetry in quarterly returns of all countries. The results are the same in both dollar-denominated and local currencies. Using a third-order Markov chain, the findings suggest the presence of an asymmetric pattern only in the quarterly dollar-denominated returns of Japan (a disclosure rank of 3) and the local currency returns of Switzerland (a disclosure rank of 1). The asymmetric return pattern of Japan is due to non-random walk process, whereas the non-random walk pattern and persistence of long-run negative returns are the cause of the asymmetric pattern of Switzerland. Both Japan and Switzerland are classified as countries with relatively low levels of disclosure. The findings based on the time reversibility test suggest that the monthly real returns in both dollar-denominated and local currencies of Germany (a disclosure rank of 2) are asymmetric. The asymmetries are consistent with the "slow-up and fast-down" pattern. These results are roughly consistent with the 
duration dependence and the variance ratio tests (Jirasakuldech and Zorn (2002)). The implication of the results will be discussed in the conclusion section.

Our paper is organized as follows: Section II presents a brief review of the relevant literature on tests for asymmetry. Section III describes the data. Section IV presents the Markov chain test procedure and the empirical results from a second and third-order Markov chain. Section V presents the time reversibility test and the empirical results. Section VI presents the conclusions of the study.

\section{Relevant Literature on Tests for Asymmetry}

Asymmetry or non-linear phenomenon has been studied extensively in many macroeconomics variables over the phases of the business cycle. The concept of "asymmetry" was first defined as the different probabilistic structure during the upswings and downswings in the economy. A sharp drop during the downturns in contrast to a gradual increase during the upturns of the economy was previously documented by Burns and Mitchell (1946), Blatt (1980), and among others as cyclical asymmetry. Recent studies examining the asymmetric or nonlinear behavior in economic time series such as the unemployment rate, output, and labor markets also found evidence consistent with asymmetric behavior (Rothman (1991), Mills (1991), (1995), Peat and Stevenson (1996), and Peel and Speight (1998)).

The concept of asymmetry is not just restricted to a quick drop and slow rise in the business cycle. Others who have provided alternative forms of asymmetry and examined this concept include Neftci (1984), Falk (1986), DeLong and Summer (1986), Sichel (1989), (1993), McQueen and Thorley (1993), and Ramsey and Rothman (1996). 
The results are mixed. According to Neftci (1984) if a series is symmetric, the transition probability of a positive first difference given two prior positive first differences is the same as the transition probabilities of a negative first difference given two prior negative differences. Using this approach, Neftci found evidence consistent with asymmetric structure in the annual U.S. unemployment rate. Falk (1986) applied Neftci's technique to real GNP, investment, and productivity in the United States, Canada, France, Italy, the United Kingdom, and West Germany but failed to reject symmetry in those series.

Delong and Summer (1986) argued that asymmetry of a business cycle would imply skewness in the distribution. Using this concept, he found strong evidence of symmetry for the GNP growth rate, a result consistent with Falk (1986). Sichel (1993) extended their work and characterized asymmetry in two forms, "deepness" and "steepness". He compared the positive slope during the economic expansion with the steeper negative slope during the economic contraction and concluded that the slope of economic growth rate during the expansion and contraction is the same.

McQueen and Thorley (1993) characterized asymmetry as "sharpness". The business cycle is asymmetric if the transition in troughs is sharp while the transition in peaks is round. They found evidence that the business cycle is characterized by "sharpness" asymmetry. The other alternative form of asymmetry defined by Ramsey and Rothman (1988), (1996) is time irreversibility. If the probabilistic structure of a time series going forward in time is the same as it is going backward in time, the series is symmetric or time reversible. Their findings suggest that many macroeconomic time series such as nominal GNP, industrial production, GNP price deflator, CPI, real wage, money, and bond yields are time irreversible. 
The concept of asymmetry, which can be defined as asymmetric transition probability, steepness, deepness, sharpness, or time irreversible, also has important implications for empirical work in finance. McQueen and Thorley (1991) were the first to adopt the Markov chain technique developed by Neftci (1984) to test the random walk hypothesis of equity prices of the value-weighted portfolio of all New York Stock Exchange (NYSE) during the period of 1947 to 1987. Their findings suggest that annual real and excess returns exhibit a nonrandom walk tendency. Low (high) returns tend to follow high (low) returns in a particular year. Applying the time reversibility test on S\&P 500 index during the period 1871 to 1988 , Ramsey and Rothman (1996) found that this stock index series is time irreversible. The asymmetry is due to nonlinearity.

\section{Data}

The data used in this study consist of two parts. The first set is the ranking of a country's disclosure levels. The relative country's disclosure is obtained from the study done by S\&B (1992). The second set consists of the end of month stock price indices including dividend income of all eight countries. Both dollar-denominated and local currency price indices are used. The stock prices data are the Capital International indices constructed by Morgan Stanley. The data were collected on-line from Morgan Stanley for the period January 1970 to August 2000.

\subsection{Country's Disclosure Ranking}

A ranking of disclosure levels is assigned to eight countries by using the financial disclosure index created by S\&B (1992). Table 1 shows the results of each country's 
disclosure level ranking (DLR) based on studies done by S\&B in 1992. In 1992, S\&B created a new country disclosure index from a survey of 142 experts who engaged in the process of listing securities in the foreign stock exchanges. The participants (63 U.S. and 79 non-U.S.) were people from different fields of business such as corporate managers, investment bankers, accountants, stock exchange officers, academicians, and so on. The financial disclosure level includes both voluntary and mandatory disclosures. These eight countries are ranked based on three criteria: statutory reporting requirements, exchange reporting requirements, and capital market expectations. The results are consistent with the previous studies of S\&B (1989) except that the order of countries within the high disclosure group is changed. The United States is the country that provides most comprehensive disclosure, followed in order by Canada, the United Kingdom, the Netherlands, France, Japan, Germany, and Switzerland.

S\&B's (1992) country disclosure rankings are used for this study for several reasons. First, they are the most comprehensive and widely used country disclosure rankings in several international accounting disclosure studies (see for example, Alford, Jones, Leftwich and Zmijewski (1993), Saudagaran and Biddle (1995), and Higgins (1998)). Second, S\&B's rankings include both voluntary and mandatory disclosures while other disclosure studies' rankings are based solely on mandatory disclosure. Third, the country disclosure index obtained by $\mathrm{S} \& \mathrm{~B}$ is the most recent country disclosure ranking and is consistent with several previous disclosure ranking studies (see for example, Lafferty and Carins (1980), Choi and Bavishi (1982), and Cairns, Lafferty and Mantle (1984)). 
Table 2 shows the summary of financial reporting requirements of eight countries prepared by Alford et al. (1993). This financial reporting summary shows the areas of diversity in accounting standards across countries. The sources of GAAP of all countries except the United States and Canada are derived from government sources only. U.S. GAAP is derived from both public (SEC) and private (FASB) sources, while Canadian GAAP is derived from a private source only. According to Ali and Hwang (2000), countries where the private sectors do not get involved in setting accounting standard are associated with less value relevance of financial reports. There is a relation among the source of GAAP, level of alignment between financial and tax accounting, and country's disclosure level. Countries with low levels of disclosure are associated with a high level of alignment between financial and tax accounting. High conformity between tax and financial report encourages firms to reduce taxes by reporting lower profit; as a result published financial reports are less value relevant (Ali and Hwang (2000)).

Table 2 also shows the diversity in frequency and timing of financial reports. U.S. and Canada require quarterly financial reports, while other countries require semiannual financial reports. Switzerland with the lowest disclosure level does not require any interim financial reports. While the U.S. allows the shortest lag in the interim report (48 days), other countries allow longer interim report lags (4 months). The annual reporting lag ranges from the shortest of 90 days (U.S.) to the longest of eight months (Japan). ${ }^{1}$

\footnotetext{
${ }^{1}$ The accounting standard in Japan is dual in the sense that the extent of disclosure in annual reports is prescribed by both the Commercial Code (CC) and the Securities and Exchange Law (SEL). The financial reports prepared under the $\mathrm{CC}$, which are distributed to the shareholders contain less information than those
} 


\subsection{Description of Morgan Stanley Capital International (MSCI) Price Indices}

The stock price indices of eight countries, namely the United States, Canada, the United Kingdom, the Netherlands, France, Japan, Germany, and Switzerland are examined. The stock price data are value-weighted indices with dividends. They are computed from end-of-month prices of a large sample of firms in each national equity market. The data during the period of January 1970 to August 2000 in both dollardenominated and local currencies were used.

Two non-parametric tests are performed on the transformed continuously compounded monthly real returns in both dollar-denominated and local currencies of eight countries. Monthly Consumer Price Index (CPI) data of each country are collected from the International Financial Statistics (IFS) Database and Handbook published by the International Monetary Fund (IMF). Continuously compounded monthly inflation rates are calculated by taking the first difference of the natural log of the monthly CPI.

MSCI Indices are constructed on a uniform basis across countries. ${ }^{2}$ The indices are constructed so as not to include stocks with multiple-listings on foreign stock exchanges. This eliminates the problem of double counting stocks. In addition, the MSCI indices do not include the stock of companies that are non-domiciled and that have high cross-ownership. Firms that have high reciprocal ownership provide a continuous flow of information among firms, making access to inside information easier and publicly available information less useful.

prepared under the SEL which are reported to the Stock Exchange, but not sent to the shareholders (Cooke (1993)).

${ }^{2}$ Construction of MSCI indices can be obtained from http://www.msci.com 
Tables 3 and 4 provide summary statistics of monthly real returns in dollardenominated and local currencies for all eight countries. The means of the stock return series in both currencies are all positive, indicating that stock markets in those countries were trending upward over the thirty-year period. When measured in dollar-denominated currency, the Netherlands (a disclosure rank of 5) has the highest average monthly returns of 0.83 percent, while Canada (a disclosure rank of 7) has the lowest average stock returns of 0.51 percent. France (a disclosure rank of 4 ) has the most volatile market as indicated by the highest standard deviation $(6.70 \%)$, while the stock returns of the United States (a disclosure rank of 8 ) have the lowest volatility (4.50\%). The results are the same in dollar and in local currencies except Japan (a disclosure rank of 3) has the lowest mean in its own currency.

The dollar-denominated real returns of all countries, except the United Kingdom and Japan, show significant negative skewness coefficients. When local currencies are used, all the countries show significant negative skewness, consistent with the presence of bubbles. The significance of the excess kurtosis coefficients of the return series of all the countries in both dollar-denominated and local currencies indicates that the return distributions have "fat tails" when compared to the normal distribution. The fat tail finding implies that price changes occasionally deviate by large amounts. High kurtosis in return series is an indication of the possible presence of bubbles. In terms of dollardenominated currency, Canada shows the highest negative skewness, while the United Kingdom shows the highest kurtosis. The United Kingdom has the highest skewness and excess kurtosis coefficients when returns in pounds are used. The large value of excess kurtosis indicates that the return data are leptokurtic with a sharper peak than Gaussian 
distributions. ${ }^{3}$ The evidence of skewness and kurtosis indicates significant third and fourth moments.

Tables 3 and 4 also provide the results of the first six sample autocorrelations and the Ljung-Box portmanteau test statistics (Q) for the sixth and twelfth-order autocorrelation for the real returns in dollar-denominated and local currencies. The first and second order autocorrelation are very small for all the countries. When the dollardenominated returns are used, the Ljung-Box (1978) portmanteau test statistic shows that the null hypothesis of no serial autocorrelation is only rejected for the returns at lag six for the United Kingdom. ${ }^{4}$ Moreover, the Ljung-Box test statistic with twelve lags indicates a presence of serial autocorrelation for the dollar-denominated returns of Japan. When the returns in local currencies are used, the Ljung-Box portmanteau test statistics with twelve lags rejects the null hypothesis of no serial correlation for the returns of the Netherlands and Switzerland at a less than five percent level of significance. The significance of skewness, kurtosis, and the Q-statistics suggests the possibility of nonrandom walk behavior in the returns.

\section{Markov Chain Test Procedure}

\subsection{Methodology}

Neftci (1984) stated that for a given time series $\left\{X_{t}\right\}$, one can define a finite state Markov process $\left\{I_{t}\right\}$ by letting one state represents an increase in $\left\{X_{t}\right\}$ and the other represent a decrease in $\left\{X_{t}\right\}$. From the process $\left\{I_{t}\right\}$, we can calculate the transition

\footnotetext{
${ }^{3}$ A Guassian distribution has a kurtosis of 3 .

${ }^{4}$ The chi-square critical values for six degree of freedom at the five and ten percent levels of significance are 12.59 and 10.64, respectively. With twelve degree of freedom, the chi-square value at the five and ten percent level of significance are 21.03 and 18.55 , respectively.
} 
probability and test for symmetry by using the likelihood ratio test. McQueen and Thorley (1991) applied the Markov chain technique to test the random walk hypothesis of U.S. stock prices and found a non-random walk return pattern.

In this paper, quarterly and monthly real returns are modeled as a two-state, second order and third order Markov chain. The tests are done on both dollardenominated and local currencies. Neftci (1984) pointed out that high frequency data (either daily, weekly, or monthly) introduce white noise on the series making asymmetric behavior less likely to be detected. ${ }^{5}$ Annual data are obviously more likely to exhibit asymmetry. ${ }^{6}$ However, the problem inherent in annual data is that the power of statistical procedure decreases as the sample size decreases. Therefore, quarterly data is the best candidate because the white noise errors tend to be averaged out.

To create a Markov chain, a continuous series of real returns is transformed to a discrete series by first defining the number of states and the choice of chain order. To test for asymmetry, an increase in one state is represented by a positive return $\left(R_{t}>0\right)$ while a decrease is represented by a negative return $\left(R_{t}<0\right)$. The finite Markov process $\left\{I_{t}\right\}$ can be defined as follows: ${ }^{7}$

(1) $I_{t}=\left\{\begin{array}{l}1 \text { if } R_{t}>0 \\ 0 \text { if } R_{t}<0\end{array}\right.$

The two-state Markov chain process $\left\{I_{t}\right\}$ can be formulated by letting $I_{t}$ equal 1(0) if the returns are positive (negative). An asymmetric behavior in the return series of each country can be investigated by observing the pattern in which the process $\left\{I_{t}\right\}$ moves

\footnotetext{
${ }^{5}$ Introducing parameters that help capture the state dependencies are needed if monthly data are used.

${ }^{6}$ According to Neftci, annual data are the most appropriate. However, only 30 annual observations are available which makes the test less likely to be reliable.

${ }^{7}$ The process $\left\{I_{\mathrm{t}}\right\}$ is stationary because $R_{\mathrm{t}}$ was found to be stationary.
} 
from one state to another. For example, during the period of upswings (a bubble grows), the process $\left\{I_{t}\right\}$ is positive and lasts longer but is negative and shorter during the period of downswings (a bubble bursts). Specifically, if a bubble is present, one would expect to observe a process $\left\{I_{t}\right\}$ that remains in state 1 longer than in state 0 . This implies that the probability of moving from state 1 to state 1 should be greater than that of moving from state 0 to state 0 . To test for asymmetry of the return series, the transition counts and transition probabilities are formed based on the behavior of process $\left\{I_{t}\right\}$. A two-state Markov chain is formed by letting the transition counts and transition probabilities vary depending on the returns of two prior states. Following McQueen and Thorley (1991)'s methodology, the transition counts $\left(N_{i j}\right.$ and $\left.M_{i j}\right)$ and probabilities $\left(\lambda_{i j}\right)$ are defined as follows:

\section{Transition Count Matrix}

Previous

States

\begin{tabular}{ll|cc}
\multicolumn{1}{c}{} & \multicolumn{1}{c}{0} & 1 \\
0 & 0 & $N_{00}$ & $M_{00}$ \\
0 & 1 & $N_{01}$ & $M_{01}$ \\
1 & 0 & $N_{10}$ & $M_{10}$ \\
1 & 1 & $N_{11}$ & $M_{11}$ \\
\cline { 3 - 4 } & &
\end{tabular}

\section{Transition Probability Matrix}

$\begin{array}{cc}\text { Previous } & \text { Current } \\ \text { States } & \text { State }\end{array}$

\begin{tabular}{ll|cc} 
& & 0 & 1 \\
0 & 0 & $\lambda_{00}$ & $1-\lambda_{00}$ \\
0 & 1 & $\lambda_{01}$ & $1-\lambda_{01}$ \\
1 & 0 & $\lambda_{10}$ & $1-\lambda_{10}$ \\
1 & 1 & & $1-\lambda_{11}$ \\
\hline
\end{tabular}

$N_{00}$ represents the number of observations in state $000 . \quad M_{00}$ represents the number of observations in state 001 . In other words, $N_{00}$ is the number of observations that have a negative return in the current state given the negative returns in the prior two states. $M_{00}$ is the number of observations that have positive return in the current state given negative returns in the prior two states. The transition probabilities $\left(\lambda_{i j}\right)$ can be defined as follows:

$$
\lambda_{00}=\operatorname{Prob}\left[I_{\mathrm{t}}=0 \mid I_{\mathrm{t}-2}=0, I_{\mathrm{t}-1}=0\right]
$$




$$
\begin{aligned}
& \lambda_{01}=\operatorname{Prob}\left[I_{\mathrm{t}}=0 \mid I_{\mathrm{t}-2}=0, I_{\mathrm{t}-1}=1\right] \\
& \text { (4) } \quad \lambda_{10}=\operatorname{Prob}\left[I_{\mathrm{t}}=0 \mid I_{\mathrm{t}-2}=1, I_{\mathrm{t}-1}=0\right] \\
& \text { (5) } \quad \lambda_{11}=\operatorname{Prob}\left[I_{\mathrm{t}}=0 \mid I_{\mathrm{t}-2}=1, I_{\mathrm{t}-1}=1\right]
\end{aligned}
$$

where $\lambda_{00}$ is the probability of obtaining a negative return in the current period given negative returns in the prior two states and $1-\lambda_{00}$ is the probability of obtaining a positive return in the current period given negative returns in the prior two states. If the returns are symmetric, the probability of observing a downswing or upswing in the current period should be similar and independent of what happened in the prior states. There are two hypotheses to be tested:

(6) Null Hypothesis 1: $\quad \lambda_{00}=\lambda_{11}$

(7) Null Hypothesis 2: $\quad \lambda_{00}=\lambda_{01}=\lambda_{10}=\lambda_{11}$

Hypothesis 1 is a specific test for a bubble. The alternative bubble hypothesis 1 suggests that if a bubble presents, the probability of observing a negative return (a bubble bursts) given an upward trend should be greater than the probability of observing a negative return given two consecutive negative returns $\left(\lambda_{00}<\lambda_{11}\right)$. The test can be performed by finding the maximum likelihood estimates (MLE) of the four transition probabilities, i.e. $\Lambda^{\prime}=\left[\lambda_{00} \lambda_{01} \lambda_{10} \lambda_{11}\right]$.

The parameters are determined by using the following log likelihood function: ${ }^{8}$

\footnotetext{
${ }^{8}$ The derivation of the log likelihood function can be determined as followed. Let $\mathrm{S}_{\mathrm{T}}=\left\{i_{1}, i_{2}, \ldots \ldots, i_{\mathrm{T}}\right\}$ represents the realization of the process $\left\{I_{t}\right\}$. If the process $\left\{I_{t}\right\}$ is a second-order Markov chain, the likelihood function can be written as $: L\left(S_{T}\right)=P\left(I_{T}=i_{T} \mid I_{T-1}=i_{T-1}, I_{T-2}=i_{T-2}\right) \ldots . . P\left(I_{3}=i_{3} \mid I_{2}=i_{2}, I_{1}=i_{1}\right) P\left(I_{2}=i_{2}, I_{1}=i_{1}\right)$. Substituting the transition probabilities as defined in equations (2) to (5) into the above equation, the likelihood function is written as: $L\left(S_{T}, \lambda_{i j}, \pi_{0}\right)=\pi_{0}\left(\lambda_{11}\right)^{n 11}\left(1-\lambda_{11}\right)^{T_{11}}\left(\lambda_{00}\right)^{n 00}\left(1-\lambda_{00}\right)^{T_{00}} x\left(\lambda_{01}\right)^{n 01}\left(1-\lambda_{01}\right)^{T_{01}}\left(\lambda_{10}\right)^{n 10}\left(1-\lambda_{10}\right){ }^{T_{10}}$
} 


$$
L\left(S_{T}, \Lambda^{\prime}, \pi_{0}\right)=\log \pi_{0}+\sum_{i j=o o}^{11} N_{i j} \log \lambda_{i j}+M_{i j} \log \left(1-\lambda_{i j}\right) .
$$

The four parameters are derived by taking the partial derivatives of the log likelihood function of equation (8) with respect to each parameter, and solving for each transition probability. Neftci (1984) indicates that $\pi_{0}$, the probability of the initial two states can be ignored when the sample size is large as is the case in this study. The maximum likelihood estimators $\hat{\lambda}_{i j}$ are derived as follows:

$$
\hat{\lambda}_{i j}=\frac{N_{i j}}{\left(N_{i j}+M_{i j}\right)} .
$$

and their asymptotic variances are

$$
\sigma^{2}\left(\hat{\lambda}_{i j}\right)=\frac{\hat{\lambda}_{i j}\left(1-\hat{\lambda}_{i j}\right)}{N_{i j}+M_{i j}}
$$

Given the estimate of the four parameters, the likelihood ratio test (LRT) of equal transition probabilities is formed.

\section{(11) $\quad$ LRT $=2[\log$ Unrestricted-Log Restricted $] \sim \chi_{n}^{2}$}

where Log Unrestricted is obtained by evaluating (8) at the unrestricted estimates and the Log Restricted is obtained by evaluating (8) at the restricted estimates of the parameters.

The LRT is asymptotically distributed $\chi_{n}^{2}$ with $n$ degree of freedom where $n$ is the number of restrictions. 


\subsection{Empirical Results}

\subsubsection{Second-Order Markov Chain}

The second-order Markov chain transition counts, transition probabilities, maximum likelihood estimates, and the likelihood ratio test for quarterly real returns in dollar-denominated and local currencies of all eight countries are reported in Tables 5 and 6, respectively. As shown in Table 5, $\lambda_{00}$ are greater than $\lambda_{11}$ for the United States, Canada, the Netherlands, France, Japan, and Switzerland, indicating an existence of positive serial dependence in the dollar-denominated quarterly real returns of these countries; whereas the United Kingdom and Switzerland show negative serial dependence. For the returns in local currency, all countries show positive serial dependence.

For the United States, quarterly real returns were negative 6 out of 16 times given two prior negative returns and were negative 18 out of 54 times given two prior positive returns. That is to say, during the period of 1970 to 2000 , the probability of observing a negative return following two consecutive negative returns is $37.50 \%$ and the probability of observing a negative return following two consecutive positive returns is $33.30 \%$. Hence, the probability of observing a positive return following two consecutive positive returns is $66.70 \%$. The results for Canada, the United Kingdom, the Netherlands, and France show only slight differences in the transition probabilities, indicating of symmetry. The probability of obtaining negative returns following two prior years of negative returns for Canada is $35.30 \%$ (6 out of 17 times), for the United Kingdom is $36.80 \%$ ( 7 out of 19 times), for the Netherlands is $35.70 \%$ (5 out of 14 times), and for France is $40.90 \%$ ( 9 out of 22 times), respectively. Given two preceding years of positive 
returns, the probability of obtaining negative returns for Canada is $34.00 \%$, for the United Kingdom is $37.80 \%$, for the Netherlands is $31.50 \%$, and for France is $40.00 \%$. These countries are categorized as countries with highly stringent disclosure regulation.

For Japan, Germany, and Switzerland, the transition probabilities are quite different. The differences between unrestricted ML estimates $\lambda_{00}$ and $\lambda_{11}$ of Japan (44.40\% and 31.80\%), Germany $(25.00 \%$ and $43.90 \%)$, and Switzerland $(42.10 \%$ and $39.00 \%$ ) are relatively large, suggesting that the return series of these countries are more likely to exhibit a non-random walk pattern. These countries are classified as countries with less stringent disclosure regulation.

For all the countries except the United Kingdom and Germany, the ML estimates of $\lambda_{00}$ and $\lambda_{11}$ indicate that the process $\left\{I_{t}\right\}$ stays in the negative state longer than the positive state which is implied by $\lambda_{00}>\lambda_{11}$ (the transition probability of moving from a negative return to a negative return is greater than that of moving from a positive return to a negative return). These countries exhibit persistence in negative returns.

To test for symmetry in the associated transition probability, we first re-estimate the value of $\hat{\lambda}_{00}$ and $\hat{\lambda}_{11}$ under the restriction that $\lambda_{00}=\lambda_{11}$ and the four parameters under the more restrictive second null hypothesis. Once the estimated values of $\hat{\lambda}_{00}$ and $\hat{\lambda}_{11}$ are found, the likelihood ratio test can be formed to test the null hypothesis of $\lambda_{00}=\lambda_{11}$ by substituting the restricted and unrestricted log likelihood values into equation (11). Under the null hypothesis that $\lambda_{00}=\lambda_{11}$, the probability of observing a negative return in the current state is the same and is independent of the returns of prior states. The symmetry restriction $\left(\lambda_{00}=\lambda_{11}\right)$ are 0.2286 for the United States, 0.2656 for Canada, 
0.2969 for the United Kingdom, 0.2059 for the Netherlands, 0.3284 for France, 0.3623 for Japan, 0.3279 for Germany, and 0.3167 for Switzerland.

To test hypothesis 2 , the symmetry restriction $\left(\lambda_{00}=\lambda_{01}=\lambda_{10}=\lambda_{11}\right)$ are tested using the same procedure. The probability of having a negative return in the current period regardless of the prior sequence of the returns is $34.17 \%$ for the United States, $36.67 \%$ for Canada, $39.17 \%$ for the United Kingdom, $32.50 \%$ for the Netherlands, 39.17 for France, $42.50 \%$ for Japan, $40.83 \%$ for Germany, and $40.00 \%$ for Switzerland. ${ }^{9}$ Given these values, the restricted and unrestricted log likelihood can be obtained. Substituting the result into (11) yields the log likelihood ratio (LRT) of 0.094 and 0.900 under the first and the more restrictive null hypothesis for the United States. The LRT of all other countries are derived by the same procedure, but the magnitudes are quite small. The pvalues and critical values reported in Table 5 also indicate that we are unable to reject the null hypothesis of symmetry for all real return series (dollar-denominated currency) of all eight countries. A similar result is found when a more restrictive null hypothesis of four equal transition probabilities is tested. Again, the null hypothesis of symmetry cannot be rejected for the real returns (dollar-denominated currency) of all eight countries.

A consistent result is found when a second order Markov chain test is applied on the real returns in local currency as shown in Table 6. Real returns of all countries show positive serial dependence. The two null hypotheses of equal transition probabilities cannot be rejected at a traditional significance level. These findings provide evidence of symmetry in the real returns of all the countries when measured in either dollar or local

\footnotetext{
${ }^{9}$ For the second-order Markov chain, the total number of observations is 120 because the first two observations are used to create the second-order Markov chain.
} 
currencies. A symmetric pattern found in the return series of all countries suggests that a bubble is less likely to be present.

To provide an assurance that the design of the test is not sensitive to the measurement of the return, a second-order Markov chain test is also performed on the monthly and annual real returns. ${ }^{10}$ Tables 7 and 8 report the second-order Markov chain test on the monthly real returns in dollar-denominated and local currencies. Both null hypotheses of symmetry cannot be rejected at the traditional significance level for either the dollar-denominated or local currencies. ${ }^{11}$ The main finding here is that the equity returns of all countries exhibit symmetric patterns, characteristics that are contrary to the presence of a bubble.

\subsubsection{Third-Order Markov Chain}

One of the criticisms of the second-order Markov chain technique is that second order Markov chain is inappropriate when there is a long-run period of the "good" or “bad" years (McQueen and Thorley (1991)). This relative long run pattern justifies the use of a higher order Markov chain, i.e. the third or fourth-order Markov chain. At least one-fourth of the runs of real returns of all countries last longer than two months. ${ }^{12}$ Therefore, the third order Markov chain is applied to reinvestigate the asymmetric behavior of the returns of all countries. To develop the third-order Markov chain test, we

\footnotetext{
${ }^{10}$ The results based on the annual returns are not reported here.

${ }^{11}$ When annual real returns are used we found evidence of asymmetry in the dollar-denominated returns only in Switzerland (a disclosure rank of 1). The null hypothesis of symmetry (four equal transition probabilities) is rejected at a p-value of 0.03 . The results using annual returns are subject to two flaws. First, too small sample size is used. Only 30 annual observations are used. Second, McQueen and Thorley (1991) pointed out that a sample size of at least 41 is large enough to exclude $\pi_{0}$ (initial state). With the sample size of $30, \pi_{0}$ (initial state) needs to be included.

${ }^{12}$ A run is a sequence of the returns that has the same sign. The total numbers of runs for each length include both positive and negative runs are counted but the results are not reported here.
} 
estimate eight parameters of transition probabilities and their asymptotic variances using the same procedure as shown in the second order Markov chain. The third-order Markov chain is different from the second-order Markov chain in that the former lets the transition probability be dependent on the sequence of three prior states rather than two prior states. ${ }^{13}$ The transition counts and transition probabilities are shown as follows:

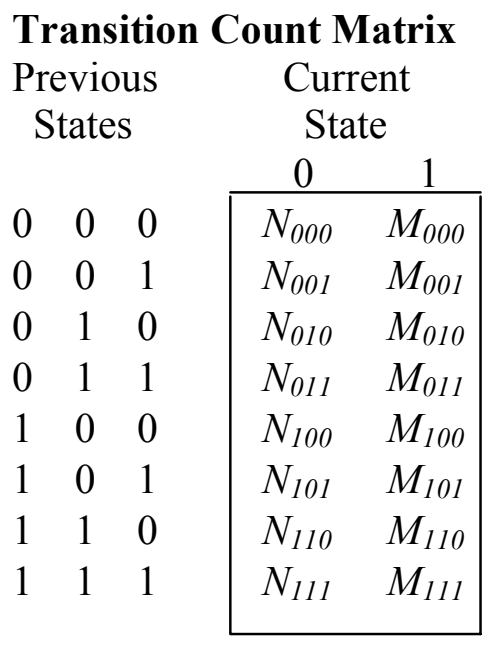

$\begin{array}{cc}\text { Transition Probability Matrix } \\ \text { Previous } & \text { Current } \\ \text { States } & \text { State }\end{array}$

The ML estimates of transition probability $\hat{\lambda}_{i j k}$ and their asymptotic variances $\sigma^{2}\left(\hat{\lambda}_{i j k}\right)$ are determined using equation (9) and (10). Table 9 reports the results of the third-order Markov chain transition counts, transition probabilities, maximum likelihood estimates, and the likelihood ratio test for the quarterly real returns in dollar-denominated currency. $^{14}$

Real returns of all the countries except Japan show the positive serial dependence. The transition probability from three prior negative returns to a negative return in the current period are $33.33 \%$ for the U.S., $33.33 \%$ for Canada, $57.10 \%$ for the U.K, $60.00 \%$ for the Netherlands, $44.40 \%$ for France, $27.30 \%$ for Japan, $40.00 \%$ for Germany, and

\footnotetext{
${ }^{13}$ However, the second and third order Markov chains are similar because both defined Markov chain into two states.
} 
$37.50 \%$ for Switzerland. After three preceding periods of positive returns, the probability that the real returns will be negative are $33.33 \%$ for the U.S., $30.00 \%$ for Canada, $28.60 \%$ for the U.K., 24.3\% for the Netherlands, $42.30 \%$ for France, 30.00\% for Japan, 34.80\% for Germany, and $36.00 \%$ for Switzerland. For the United Kingdom and the Netherlands, the probability of seeing a negative return after three sequences of negative returns is about twice as large as the probability of obtaining a negative return after three sequences of positive returns. The magnitude of the difference in transition probability for other countries is relatively small.

To test hypothesis 1 in which the restriction on the transition probability $\lambda_{000}=\lambda_{111}$ is imposed, the restricted ML estimates are first estimated. The constrained restriction estimates are $33.33 \%$ for the U.S., $30.56 \%$ for Canada, $34.29 \%$ for the U.K., $28.57 \%$ for the Netherlands, $42.86 \%$ for France, $29.27 \%$ for Japan, $35.71 \%$ for Germany, and $36.36 \%$ for Switzerland.

To test hypothesis 2 , in which the restriction on the transition probability $\lambda_{000}=\lambda_{001}=\lambda_{010}=\lambda_{011}=\lambda_{100}=\lambda_{101}=\lambda_{110}=\lambda_{111}$ is imposed, the restricted MLE are estimated. This restriction in hypothesis 2 implies that the probability of observing a negative or positive return in the current state should be the same irrespective to the sequence in the prior states. These transition counts are translated into restricted transition probability of $34.45 \%$ for the U.S., $36.97 \%$ for Canada, $39.49 \%$ for the U.K., $32.77 \%$ for the Netherlands, $39.49 \%$ for France, $42.02 \%$ for Japan, $41.18 \%$ for Germany, and $40.34 \%$ for Switzerland. Substituting the restricted and unrestricted log likelihood function in (11) yields the LRT for each country. The null hypothesis of symmetry for

\footnotetext{
${ }^{14}$ The total transition counts are 119 because the first three observations are used to create third-order
} 
Japan $(\mathrm{LRT}=12.045)$ is rejected at 10 percent significance level. The asymmetry is due to the non-random walk pattern.

Table 10 reports the third-order Markov chain results for the real returns in local currency. A positive serial dependence is present in the real returns of all countries except Japan. The null hypothesis of symmetry $\lambda_{000}=\lambda_{111}$ is rejected in favor of $\lambda_{000}>\lambda_{111}$ for Switzerland under the first null hypothesis at a stronger p-value of 0.03 . The rejection is due to the non-random walk pattern and persistence of negative returns. The persistence of negative returns found to cause asymmetry merely indicates the tendency to depart from the fundamental value.

Modeling the return process as a third-order Markov chain with monthly data suggests strong asymmetry in real returns of the United States and the Netherlands (local currency). The results are shown in Tables 11 and 12. The asymmetries are due to the persistence of the runs of negative returns, not the presence of a bubble.

\section{Time Reversibility Test}

Time reversibility, a different methodology, is employed to empirically determine whether the return series can be characterized by a non-linear or asymmetric representation. Any time series is time reversible (symmetric) if the probabilistic structure going forward in time is the same as that of going backward in time (Ramsey and Rothman (1988), (1996)). If the structures are different, the time series is said to be time irreversible (asymmetric). ${ }^{15}$ The concept of "time reversibility" is used in this

Markov chain.

${ }^{15}$ According to Ramsey and Rothman (1988), the concept of time reversible is different from the notion of linearity. Some linear time series are time reversible but others are not. Therefore, a test for time irreversibility is not the same as a test for nonlinearity. 
paper to examine whether such asymmetry were present in the returns of any country.

The possible existence of a speculative bubble and its crash in the stock markets suggests that an increase in stock prices is slow whereas a decrease in stock prices is rapid. In other words, the presence of bubbles indicates an asymmetry in the return series.

\subsection{Methodology}

Ramsey and Rothman (1988), (1996) defined the property of time reversibility as follows:

Definition 1: A time series $\left\{X_{t}\right\}$ is time reversible if for every positive integer $\mathrm{n}$, every $t_{1}, t_{2}, \ldots \ldots \ldots . . ., t_{n} \in R$, and all $m \in N$, the vectors $\left(X_{t_{1}}, X_{t_{2}}, \ldots \ldots \ldots . X_{t_{n}}\right)$ and $\left(X_{-t_{1}+m}, X_{-t_{2}+m}, \ldots \ldots \ldots \ldots . ., X_{-t_{n}+m}\right)$ have the same joint probability distributions.

According to this definition, any time series which is time reversible is also stationary. ${ }^{16}$ To show that a particular time series is stationary and time reversible, a pair of moments from its joint probability distributions must be tested for equality. The equality between two moments can be established as follows:

Theorem 1: Let $\left\{X_{t}\right\}$ be a stationary time series with mean zero and let the joint probability distribution of $\left(X_{t}, X_{t-k}\right)$ and $\left(X_{t-k}, X_{t}\right)$ be uniquely characterized by the respective sequence of moments and cross moment of $X_{t}$ and $X_{t-k}$. Then, $\left\{X_{t}\right\}$ is time reversible only if

$$
\begin{aligned}
& E\left[X_{t}^{i} \cdot X_{t-k}^{j}\right]=E\left[X_{t}^{j} \cdot X_{t-k}^{i}\right] \text { or, } \\
& \gamma_{i, j}=E\left[X_{t}^{i} \cdot X_{t-k}^{j}\right]-E\left[X_{t}^{j} \cdot X_{t-k}^{i}\right]=0 .
\end{aligned}
$$

for all $i, j, k \in N$, where the expectation is taken with respect to each respective joint distribution.

\footnotetext{
${ }^{16}$ According to Ramsey and Rothman (1988), a non-stationary time series is time irreversible.
} 
Definition 2: A stationary mean-zero process is said to be time reversible to order $m$ and degree $K$ if condition (12) holds for all $i, j, k \in N$ with $i+j \leq m$ and $k \leq K$.

According to Ramsey and Rothman (1996), $m=3$ provides a sufficient condition to detect for time irreversibility. They defined the symmetric bicovariance functions, $\hat{\gamma}_{2,1}(k)$, in the case of $i=2$ and $j=1$ as follows: ${ }^{17}$

$$
\gamma_{2,1}(k)=\left\{E\left[X_{t}^{2} \cdot X_{t-k}\right]-E\left[X_{t} \cdot X_{t-k}^{2}\right]\right\}
$$

It follows that if $\left\{X_{t}\right\}$ is time reversible, then $\gamma_{2,1}(k)=0 \forall k \in N$.

The time reversibility (TR) test statistics $\hat{\gamma}_{2,1}(k)$, are then constructed by taking the difference of a sample estimate of $\hat{\beta}_{2,1}(k)$ and $\hat{\beta}_{1,2}(k)$ of the symmetric-bicovariance function as defined in equation (15) and (16), respectively.

$$
\begin{aligned}
& \hat{\beta}_{2,1}(k)=(T-k)^{-1} \sum_{t=k+1}^{t=T} X_{t}^{2} \cdot X_{t-k}, \\
& \hat{\beta}_{1,2}=(T-k)^{-1} \sum_{t=k+1}^{t=T} X_{t} \cdot X_{t-k}^{2}, \text { for all integer values of } k . \\
& \hat{\gamma}_{2,1}(k)=\hat{\beta}_{2,1}(k)-\hat{\beta}_{1,2}(k) .
\end{aligned}
$$

If the null hypothesis of time reversibility is true, the expected value of $\hat{\gamma}_{2,1}(k)$ should be zero for all lag $k$. If this does not hold for some lag $k$, it provides evidence of time irreversibility.

We first calculate the TR test statistics, $\hat{\gamma}_{2,1}(k)$, on the raw data (real returns) for eight countries. Then, $\hat{\gamma}_{2,1}(k)$, is standardized by dividing the TR test statistics by

\footnotetext{
${ }^{17}$ According to Ramsey and Rothman (1996), the bicovariance (third-order moment) is sufficient in examining for time reversibility. The higher moments can be used; however, the estimate of higher moments is less precise due to the insufficient degrees of freedom in the series to be examined.
} 
$\operatorname{var}\left[\hat{\gamma}_{2,1}(k)\right]^{1 / 2}$, where $\operatorname{var}\left[\hat{\gamma}_{2,1}(k)\right]^{1 / 2}$ is estimated via Monte Carlo simulation. The significance of the standardized TR test statistics is judged by using the resulting sampling distribution of the standardized TR statistics estimated via Monte Carlo simulation.

If time reversibility is rejected on the raw data, applying the TR test on the ARMA residuals will provide information as to the source of asymmetry. If the null hypothesis of time reversibility is rejected under the ARMA residuals, the series is of Type I time irreversible; that is, asymmetry is caused by the nonlinearity. If we fail to reject the null hypothesis of time reversibility, the series of Type II time irreversible; that is asymmetry is due to the non-Gaussian innovations.

In addition, the signs of TR test statistic $\hat{\gamma}_{2,1}(k)$ provides information on the pattern of the up-and-down trends. If the signs of TR test statistics are negative at the initial lags, it indicates the "fast-up and slow-down" asymmetric pattern. In contrast, if the signs of TR test statistics are positive at the initial lags, asymmetry of the "slow-up and fast-down" pattern is more likely. Therefore, if the real returns of countries with relatively low disclosure levels are characterized by "slow-up and fast-down", as implied by the positive TR values, it suggests the possible presence of speculative bubbles in those countries.

\subsection{Model Estimation}

The time reversibility test requires the time series being investigated to be stationary. The Augmented Dickey-Fuller and Phillips-Perron unit root tests performed on the first difference of the log of the indices value strongly reject the null hypothesis of a unit root, suggesting the return series are stationary. Once the stationary property is 
established, the TR test statistics in equation (17) is calculated on the actual data for lag $k=1$ to $25{ }^{18}$

To obtain the standardized TR test statistics $\left(\hat{\gamma}_{2,1}(k) / \operatorname{var}\left[\hat{\gamma}_{2,1}(k)\right]^{1 / 2}\right)$, we run a Monte Carlo simulation to estimate $\operatorname{var}\left[\hat{\gamma}_{2,1}(k)\right]^{1 / 2}$. We first identify the autoregressive (AR) and the moving average (MA) terms using a number of criteria: the Akaike Information Criterion (AIC), the Schwartz Information Criterion (SBC), and the absence of serial correlation in the residuals. The estimated ARMA model and the residual diagnostics, including the Ljung-Box Q statistic for sixth and twelfth-order autocorrelation of all the countries in the dollar-denominated and local currencies, are shown in Tables 13 and 14, respectively. These diagnostics suggest different ARMA models for the real returns of different countries, and the reported residuals suggest no remaining correlation. ${ }^{19}$

The coefficient values and the estimated innovations from the fitted models are used to generate an additional 368 data point. A Monte Carlo simulation is performed 1,000 times. The TR test statistics $\hat{\gamma}_{2,1}(k)$ for lag 1 to 25 for each series are estimated. Given 1,000 estimated TR test statistics, the variances of $\hat{\gamma}_{2,1}(k)$ for each lag are calculated..$^{20}$ The standardized TR test statistics; that is $\hat{\gamma}_{2,1}(k) / \operatorname{var}\left[\hat{\gamma}_{2,1}(k)\right]^{1 / 2}$ are then estimated. The sample distributions of the estimated standardized TR test statistics are constructed. The null hypothesis of time reversibility or $\hat{\gamma}_{2,1}(k)=0$ for all $k$ is tested

\footnotetext{
${ }^{18}$ Ramsey and Rothman (1996) suggested the use of only five lags to test for time reversibility for annual data. They pointed out that five lags provide sufficient evidence on the reversibility. Therefore, if the null hypothesis of time reversibility is not rejected, the series is said to be time reversible to order 3 and degree 5 , where the first number represents the order of the moments and the second number represents the numbers of lag period.

${ }^{19}$ The uncorrelated residuals rather than the significance of the coefficients are important at this stage.
} 
using the empirical sample distribution generated via Monte Carlo simulations. The results of the time reversibility test for the real returns of all eight countries in dollardenominated and local currencies are reported in Tables 15 and 16, respectively.

McQueen (1992), Richardson (1993), and Ramsey and Rothman (1996) pointed out that single horizon statistics may provide a misleading result due to the plausible interdependency among the statistics at different horizons. To address this issue, we also test the significance of the largest TR test statistics for each country using the entire sample distribution of $\hat{\gamma}_{2,1}(k)$ for 25 lags. The P-values, which are the probability of obtaining the largest $\hat{\gamma}_{2,1}(k)$ out of 25 trials, are estimated from the sample distribution of the statistics from the combined different horizons.

If the null hypothesis of time reversibility is rejected, we then test whether the irreversibility is due to the nonlinearity (Type I time irreversibility) or the linearity but non-Gaussian innovations (Type II time irreversibility). To differentiate between Type I and Type II time irreversibility, the TR test statistics for each lag are calculated on the ARMA residuals, and are standardized by the $\operatorname{var}\left[\hat{\gamma}_{2,1}(k)\right]^{1 / 2}$ where $\operatorname{var}\left[\hat{\gamma}_{2,1}(k)\right]^{1 / 2}$ is calculated via Theorem 2 .

Theorem 2: Let $\left\{X_{t}\right\}$ be a stationary sequence of independently and identically distributed random variables (IID standard errors) for which $E\left[X_{t}\right]=0 \forall t$ and assume $E\left[X_{t}^{4}\right] \prec \infty$. Then,

$$
\operatorname{var}\left[\hat{\gamma}_{2,1}(k)\right]^{1 / 2}=2\left(\mu_{4} \mu_{2}-\mu_{3}^{2}\right) /(T-k)-2 \mu_{2}^{3}(T-2 k) /(T-k)^{2},
$$
where $\mu_{2}=E\left[X_{t}^{2}\right], \mu_{3}=E\left[X_{t}^{3}\right]$, and $\mu_{4}=E\left[X_{t}^{4}\right]$.

\footnotetext{
${ }^{20} \operatorname{var}\left[\hat{\gamma}_{2,1}(k)\right]$ is calculated using a traditional variance formula.
} 
According to Ramsey and Rothman (1996) if the process is Type II time irreversibility, testing the residuals from an estimated ARMA model for time irreversibility will most of the time fail to reject the null hypothesis of time reversibility. The reason is that residuals from the fitted ARMA model are independently and identically distributed. On the other hand, if the process is Type I time irreversibility, the approximation via an $\operatorname{ARMA}(p, q)$ will reduce the power of the test and, hence, results in rejecting the null hypothesis of the time reversibility on the residuals. Therefore, if the null hypothesis of the time reversibility is rejected under both the raw data and ARMA residuals, the rejection indicates the series is of Type I time irreversibility. On the other hand, if it is rejected on the raw data but fail to reject on the ARMA residuals, it indicates Type II time irreversibility. If the return process of countries with low disclosure levels is characterized by Type I time irreversibility; that is, the irreversibility is due to the nonlinearity inherent in the model, it is an indication for an existence of a bubble. The TR test statistics for ARMA residuals using IID standard errors are reported in Tables 17 and 18 for real returns in dollar-denominated and local currencies, respectively. ${ }^{21}$

\subsection{Empirical Results}

The results of the TR test on the raw data and the P-value of the largest standardized TR test statistic show evidence of time irreversibility in all countries in both currencies, indicating that the return patterns are asymmetric. The asymmetric return pattern suggests that the upward and downward movement of stock prices exhibit

\footnotetext{
${ }^{21}$ To identify the critical regions, we rely on the asymptotic normality of the statistics. With the standardization we applied on the TR test statistics, we use the $\mathrm{N}(0,1)$ normal distribution as suggested by Ramsey and Rothman (1996). The P-Values of the largest standardized TR test statistics are estimated via Monte Carlo distribution formulated in the first stage.
} 
different behavior. The null hypothesis of the time reversibility $\left(\hat{\gamma}_{2,1}(k)=0\right)$ to order 3 and degree 25 is rejected at less than 1 percent significance level for at least three lags for the real returns in both currencies of all the countries. ${ }^{22}$

Figures 1 and 2 depict the plots of the estimated TR test statistics on the raw data versus the lags for all eight countries in dollar-denominated and local currencies, respectively. It appears that the rejection for time reversibility occurs at most of the lags for a group of countries with relatively high disclosure levels, while the rejection occurs only at a few lags for countries with relatively low disclosure. The non-linear effect tends to exert strong influence on the returns of the United States, Canada, the United Kingdom, and the Netherlands at the earlier lag; and the effect is concentrated at almost every lag for the United Kingdom. For France, Germany, and Switzerland, the concentration of the non-linear effects occurs at later lags.

When the TR tests are applied on the ARMA residuals, the null hypothesis of time reversibility is also rejected at less than the 1 percent significance level for the dollar-denominated returns of all countries. This suggests that the dollar-denominated real returns of all countries are asymmetric. The results in Tables 17 and 18 suggest that the time irreversibility or asymmetric pattern is driven by the non-linearity; that is they are Type I time irreversibility. Figures 3 and 4 show the plots of the estimated TR test statistics on the ARMA residuals versus the lags of returns in the dollar-denominated and local currencies, respectively. The rejection occurs only at a few lags. The presence of asymmetry or non-linearity implied by the TR statistics for all eight countries suggests the existence of a bubble. However, when the local currency is used the null hypothesis

\footnotetext{
${ }^{22}$ The P-value of the largest standardized TR test statistic is used.
} 
of time reversibility is rejected for the real returns of all countries except the Netherlands. The null hypothesis of time reversibility is rejected on the raw data but not on the ARMA residuals for the Netherlands. We fail to reject the null hypothesis of time reversibility on the ARMA residuals at any lag for the Netherlands.

The signs of TR test statistics are mostly negative for the real returns of all countries except Germany. The results are consistent for both currencies. Therefore, the real returns series (dollar-denominated and local currencies) of the United States, Canada, the United Kingdom, the Netherlands, France, Japan, and Switzerland exhibit the "fast-up and slow-down", while Germany (a disclosure rank of 2) displays the "slow-up and fastdown" asymmetric patterns. Only Germany shows the pattern that is consistent with the presence of a bubble. The results are invariant when the time reversibility tests are applied on the raw data and the ARMA residuals except that the Netherlands shows an anomalous result in real returns (local currency). The asymmetric pattern found for the United States when the MSCI data is used in this paper confirms the result found by Ramsey and Rothman (1988), (1996) who found evidence of time irreversibility in the CRSP and S\&P 500 index.

\section{Conclusions}

This research investigates if financial reporting and its regulation has any effect on the likelihood of a speculative bubble. We examine whether stock prices of firms in countries with low levels of disclosure or less stringent disclosure requirements are more prone to experience bubbles. The major stock markets of eight countries with various 
degrees of disclosure levels are examined. The relative levels of financial information disclosure are obtained from the study done by Saudagaran and Biddle (1992).

Using a third-order Markov chain, this study has shown that the quarterly real returns of Japan (dollar-denominated currency) and Switzerland (local currency), countries with relatively low disclosure levels, exhibit an asymmetric pattern. The asymmetric pattern of Japan is induced by the nonrandom walk pattern of the returns; whereas, asymmetric pattern of Switzerland is caused by the nonrandom walk pattern and the persistence of negative returns. The Markov chain tests also confirm the previous findings from the duration dependence and the variance ratio tests (Jirasakuldech and Zorn (2002)). The findings based on the duration dependence test indicate positive duration dependence in the dollar-denominated real returns of Japan. The variance ratio test suggests that the Japanese stock price indices in both currencies do not follow a random walk and exhibit positive serial correlation.

The empirical results based on the time reversibility test indicate that the real returns (dollar-denominated and local currencies) of all countries except the Netherlands show evidence of asymmetry. The asymmetric return patterns are caused by the nonlinearity. The "slow-up and fast-down" dynamics, consistent with a bubble is found to characterize the asymmetric return patterns of Germany. Germany is classified as a country with low levels of disclosure. The results reported here are suggestive but not conclusive. The results suggest that the levels of disclosure may affect the likelihood of bubbles. 


\section{References}

Alford, A.; J. Jones; R. Leftwich; and M. Zmijewski. "The Relative Informativeness of Accounting Disclosures in Different Countries." Journal of Accounting Research, 31 (1993), 183-223.

Ali, A. and L. S. Hwang. "Country-Specific Factors Related to Financial Reporting and the Value Relevance of Accounting Data." Journal of Accounting Research, 38 (2000), 1-21.

Barrett, M. E. "The Impact of Disclosure in Annual Reports of Large Companies in Seven Countries." The International Journal of Accounting Education and Research, 12 (1977), 1-25.

Biddle, G. C., and S. M. Saudagaran. "The Effects of Financial Disclosure Levels on Firms' Choices Among Alternative Foreign Stock Exchanges." Journal of International Financial Management and Accounting, 1 (1989), 55-87.

Blatt, J. M. "On the Frisch Model of Business Cycle." Oxford Economic Papers, 32 (1980), 467-479.

Burns, A. F., and W. C. Mitchell. "Measuring Business Cycles.” New York: Columbia University Press, 1946.

Cairns, D.; M. Lafferty; and P. Mantle. Survey of Accounts and Accountants 1983-84, London, England: Lafferty Publications, 1984.

Chan, K.; G. McQueen; and S. Thorley, "Are There Rational Speculative Bubbles in Asian Stock Markets?” Pacific-Basin Finance Journal, 6, (1998), 125-151.

Choi, F. D. S., and V. B. Bavishi, "Diversity in Multinational Accounting." Financial Executive, (1982), 45-49.

Cooke, T. E. "Disclosure in Japanese Corporate Annual Reports." Journal of Business Finance and Accounting, 20 (1993), 521-535.

DeLong, J. B., and L. H. Summers. “Are Business Cycles Symmetrical?” In The American Business Cycle, edited by R. J. Gordon. Chicago: National Bureau of Economic Research and University of Chicago Press, 1986.

Doupnik, T. S., and S. B. Salter. "External Environment and Accounting Practice: A Preliminary Test of a General Model of International Accounting Development." The International of Accounting Education and Research, 30 (1995), 189-207.

Falk, B. "Further Evidence on the Asymmetric Behavior of Economic Time Series over the Business Cycle.” Journal of Political Economy, 94 (1986), 1096-1109. 
Fama, E. F., and K. R. French. "Permanent and Temporary Components of Stock Prices" Journal of Political Economy, 96 (1988), 246-273.

Greenspan, A. "Statement to The U.S. Senate Committee on the Budget." Federal Reserve Bulletin, 84 (1998), 936-938.

Higgins, H. N. "Analyst Forecasting Performance in Seven Countries.” Financial Analysts Journal, (1998), 58-62.

Jirasakuldech, B., and T. Zorn "Financial Disclosure and Speculative Bubbles: An International Comparison." Presented at the Financial Management Association 2002 .

Kleidon, A. W. "Variance Bounds Tests and Stock Price Valuation Models." Journal of Political Economy 94, (1986), 953-1001.

Lafferty, M., and D. Cairns, Financial Times Survey of Annual Reports 1980, London, England: Financial Times Business Information, 1980.

LeRoy, S. F., and R. D. Porter. "The Present-Value Relation: Tests Based on Implied Variance Bounds." Econometrica, 49 (1981), 555-574.

Lo, A. W., and A. C. MacKinlay. "Stock Market Prices Do Not Follow Random Walks: Evidence from a Simple Specification Test.” Review of Financial Studies, 1 (1988), 897-916.

Lo, A. W., and A. C. MacKinlay. "An Econometric Analysis of Nonsynchronous Trading." Journal of Econometrics, 45 (1990a), 897-916

MacDonald, S. B. “Transparency in Thailand's 1997 Economic Crisis: The Significance of Disclosure." Asian Survey, 38 (1998), 688-703.

McQueen, G. "Long-Horizon Mean-Reverting Stock Prices Revisited." Journal of Financial and Quantitative Analysis, 27 (1992), 1-18.

McQueen, G., and S. Thorley. "Are Stock Returns Predictable? A Test Using Markov Chains.” Journal of Finance, 66 (1991), 239-263.

McQueen, G., and S. Thorley. “Asymmetric Business Cycle Turning Points.” Journal of Monetary Economics, 31 (1993), 341-362.

McQueen, G., and S. Thorley. "Bubbles, Stock Returns, and Duration Dependence." Journal of Financial and Quantitative Analysis, 29 (1994), 379-401.

Mills, T. C. "Nonlinear Time Series Models in Economics." Journal of Economic Surveys, 5 (1991), 215-242. 
Mills, T. C. "Are There Asymmetries or Nonlinearities in UK Output?" Applied Economics, 27 (1995), 1211-1217.

Mueller, G. G.; H. Gernon; and G. Meek. Accounting: An International Perspective. New York: Business One Irwin, 1994.

Neftci, S. N. "Optimal Prediction of Cyclical Downturns." Journal of Economic Dynamics and Control, 92 (1982), 225-241.

Neftci, S. N. "Are Economic Time Series Asymmetric over the Business Cycle?" Journal of Political Economy, 92 (1984), 307-328.

Pratt, J., and G. Behr. "Environmental Factors, Transaction Costs, and External Reporting: A Cross-National Comparison." The International Journal of Accounting, (1987), 1-24.

Peat, M., and M. Stevenson. "Asymmetry in the Business Cycle: Evidence from the Australian Labour Market." Journal of Economic Behavior \& Organization, 30 (1996), 353-368.

Peel, D. A., and A. H. Speight. "The Nonlinear Time Series Properties of Unemployment Rates: Some Further Evidence." Applied Economics, 30 (1998), 287-294.

Poterba, J. M., and L. Summers. "Mean Reversion In Stock Prices: Evidence and Implications." Journal of Financial Economics, 22 (1988), 27-59.

Prowse, S. D. "The Structure of Corporate Ownership in Japan.” Journal of Finance, 3 (1992), 1121-1140.

Ramsey, J. B., and P. Rothman. "Characterization of the Time Irreversibility of Economic Time Series: Estimators and Test Statistics.” Manuscript, C.V. Starr Center research Report no. 88-39, Department of Economics, New York University, 1988.

Ramsey, J. B., and P. Rothman. "Time Irreversibility and Business Cycle Asymmetry." Journal of Money, Credit, and Banking, 28 (1996), 1-21.

Richardson, M. “Temporary Components of Stock Prices: A Skeptic's View.” Journal of Business and Economic Statistics, 11 (1993), 199-208.

Rothman, P. "Further Evidence on the Asymmetric Behavior of Unemployment Rates on Business Cycle." Journal of Macroeconomics, 13 (1991), 291-298.

Saudagaran, S. M., and G. C. Biddle. "Financial Disclosure Levels and Foreign Stock Exchange Listing Decisions." Journal of International Financial Management and Accounting, 4 (1992), 106-148. 
Saudagaran, S. M., and G. C.Biddle. "Foreign Listing Location: A Study of MNCs And Stock Exchanges in Eight Countries." Journal of International Business Studies, (1995), 319-341.

Schieneman, G. S. "International Accounting: Issues and Perspective." Journal of Accounting Auditing \& Finance, 3 (1979), 21-30.

Sichel, D. E. "Business Cycle Asymmetry: A Deeper Look." Economic Inquiry, 31 (1993), 224-236.

Shiller, R. J. "Do Stock Prices Move Too Much to be Justified by Subsequent Changes in Dividends?" American Economic Review, 71 (1981), 421-436.

Shiller, R. J. "Rational Expectations and the Dynamic Structure of Macroeconomic Models: A Critical Review.” Journal of Monetary Economics, 5 (1978), 1-44.

Welsh, A. K., and R. Jernigan. "A Statistic to Identify Asymmetry Time Series." American Statistical Association 1983 Proceedings of the Business and Econometrics Section (1983), 390-395.

Zeff, S. A. 1972. Forging Accounting Principles in Five Countries. Champaign, IL: Stipes

Zhang, P. G. IMF And The Asian Financial Crisis. World Scientific Asian Economic Profiles, London, England (1998). 
Table 1

\section{Country Disclosure Level Ranks ${ }^{1}$ \\ Saudagaran \& Biddle (1992)}

\begin{tabular}{lcc}
\hline & $\begin{array}{c}\text { Overall }^{2} \\
\text { Disclosure } \\
\text { Levels }\end{array}$ & $\begin{array}{c}\text { Disclosure }^{3} \\
\text { Level } \\
\text { Rank (DLR) }\end{array}$ \\
\hline The United States & 7.28 & 8 \\
Canada & 6.41 & 7 \\
The United Kingdom & 6.02 & 6 \\
The Netherlands & 4.75 & 5 \\
France & 4.17 & 4 \\
Japan & 3.83 & 3 \\
Germany & 3.81 & 2 \\
Switzerland & 2.60 & 1 \\
& & \\
\hline
\end{tabular}

1. The country's disclosure ranking is obtained from the study done be by Saudagaran and Biddle (1992). The country's disclosure rank is based on the survey results of 142 experts.

2. Overall disclosure level is based on three areas of disclosure: statutory reporting requirement, exchange reporting requirement, and capital market expectation. See original paper for the score of disclosure in each area.

2 The higher DLR indicates higher disclosure level where ' 8 ' (' 1 ') represent the highest (lowest) disclosure level. The DLR provided by this survey is the same as the DLR conducted in 1989 except the rank for Canada is changed from 5 to 7. 


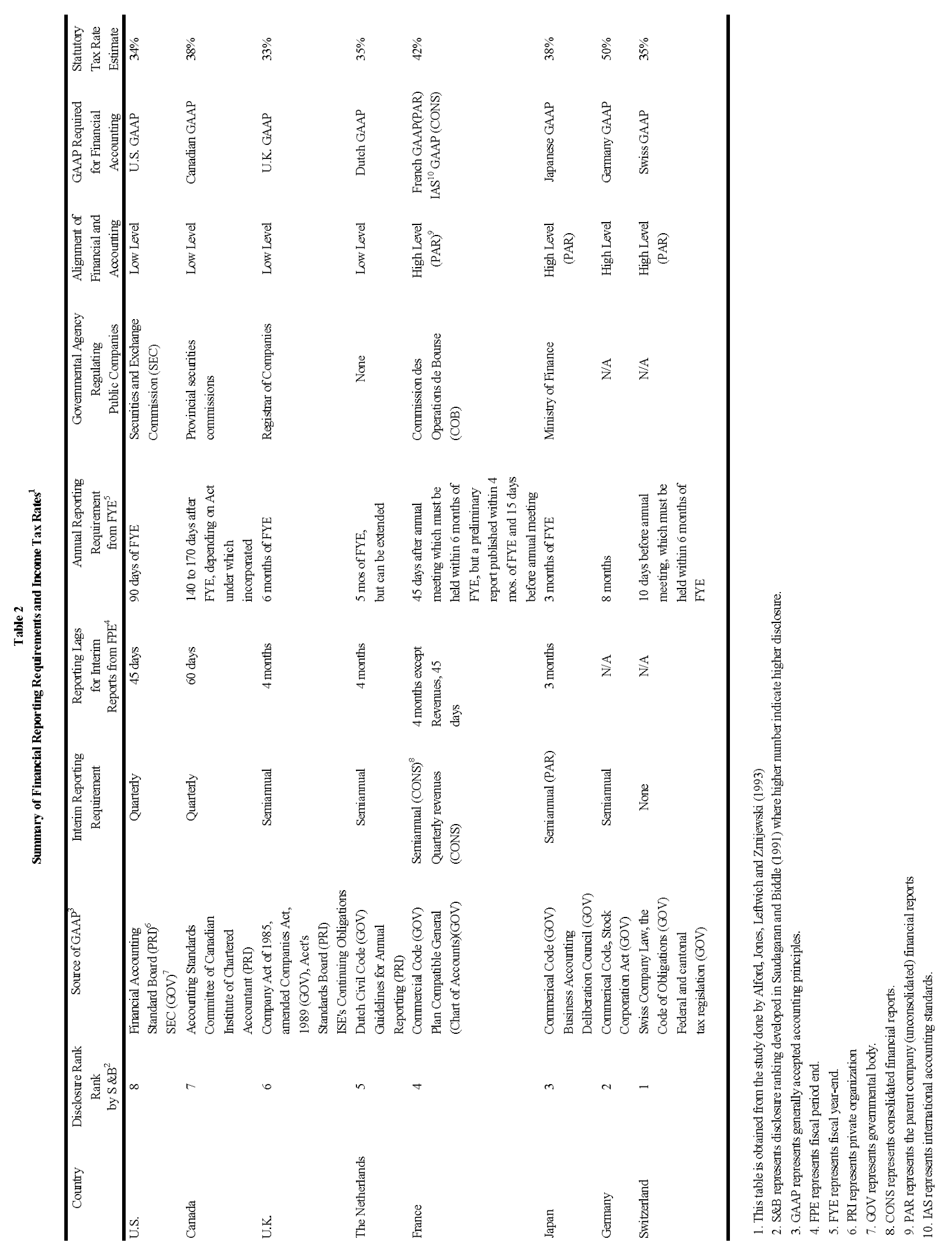




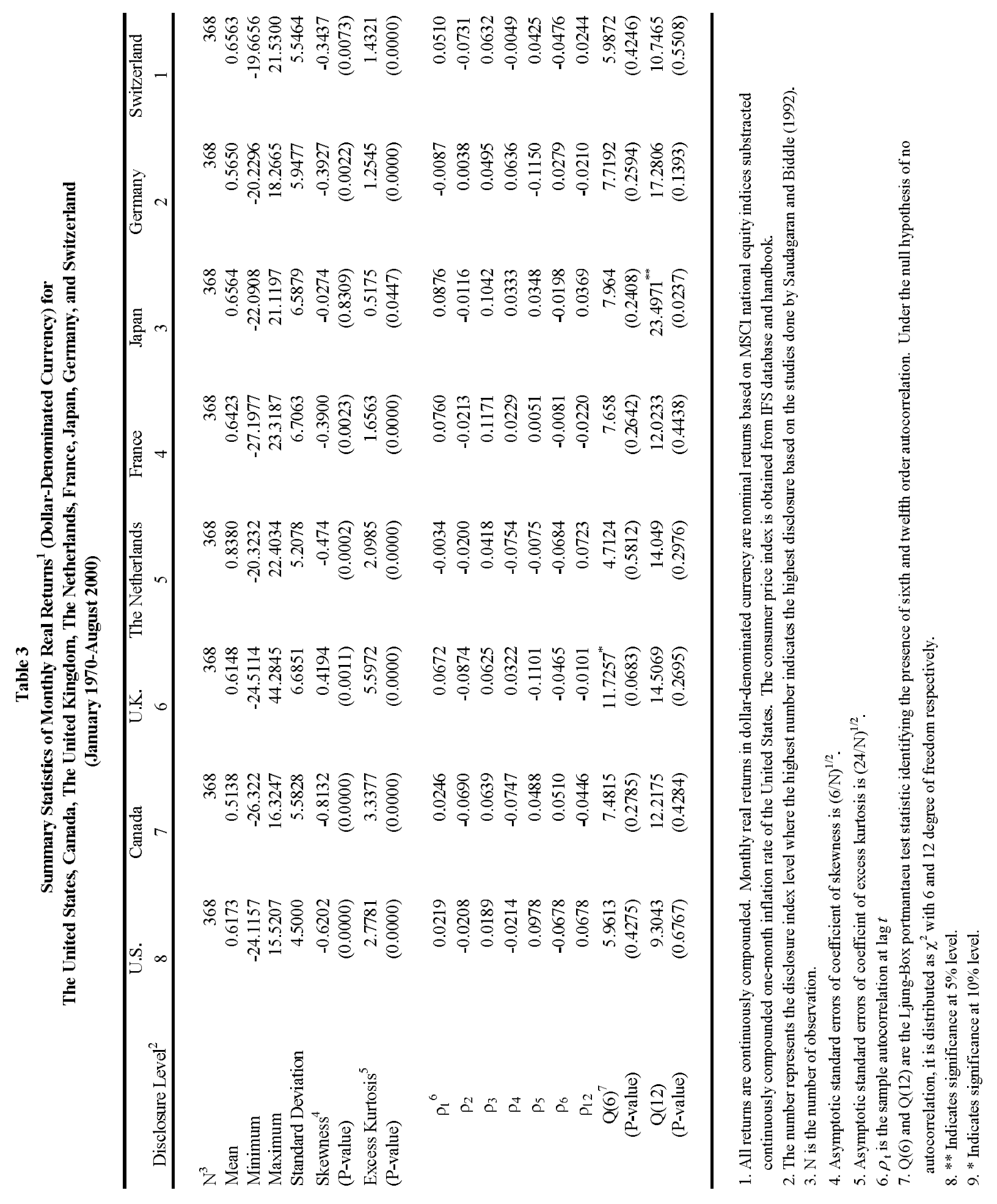




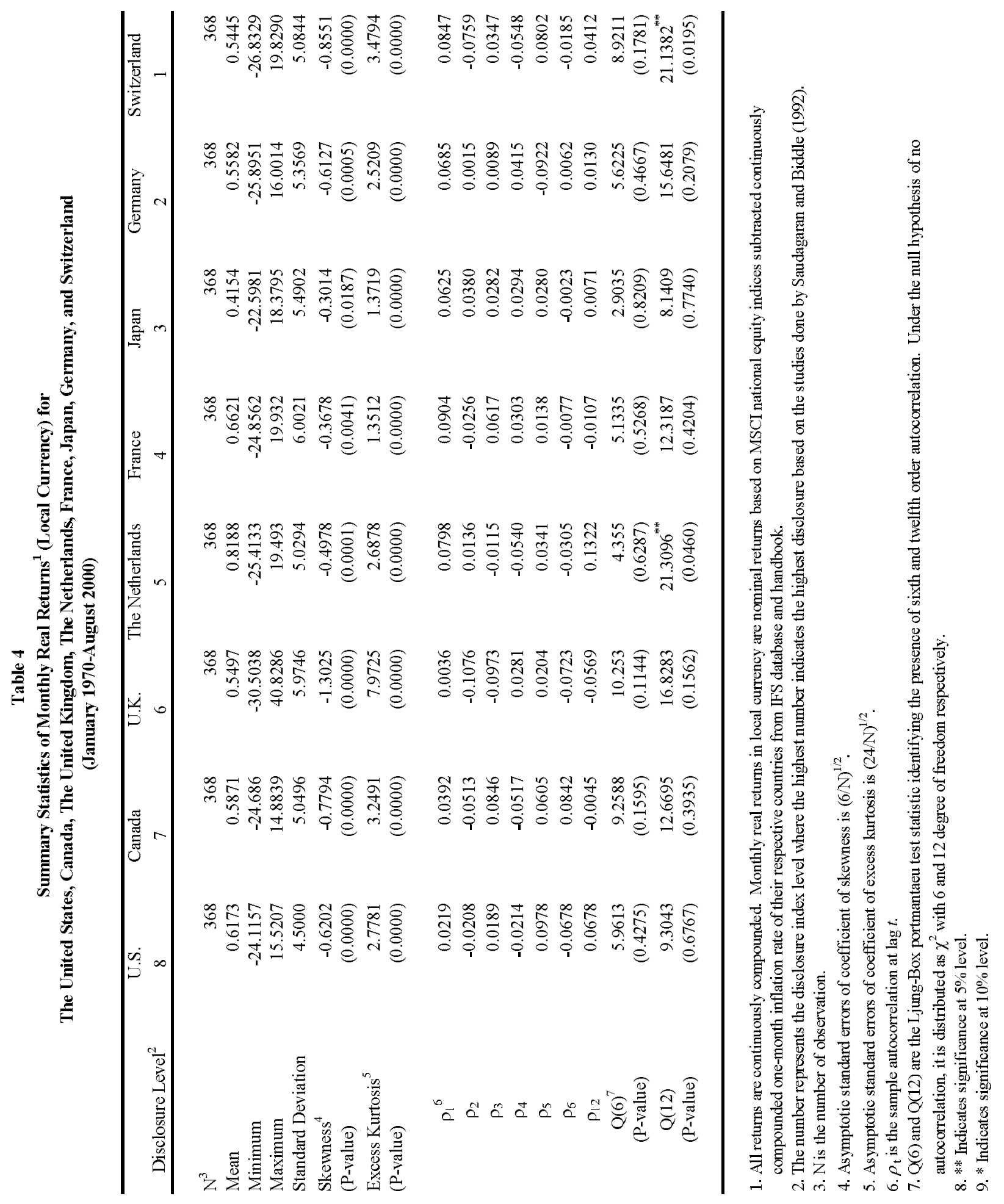




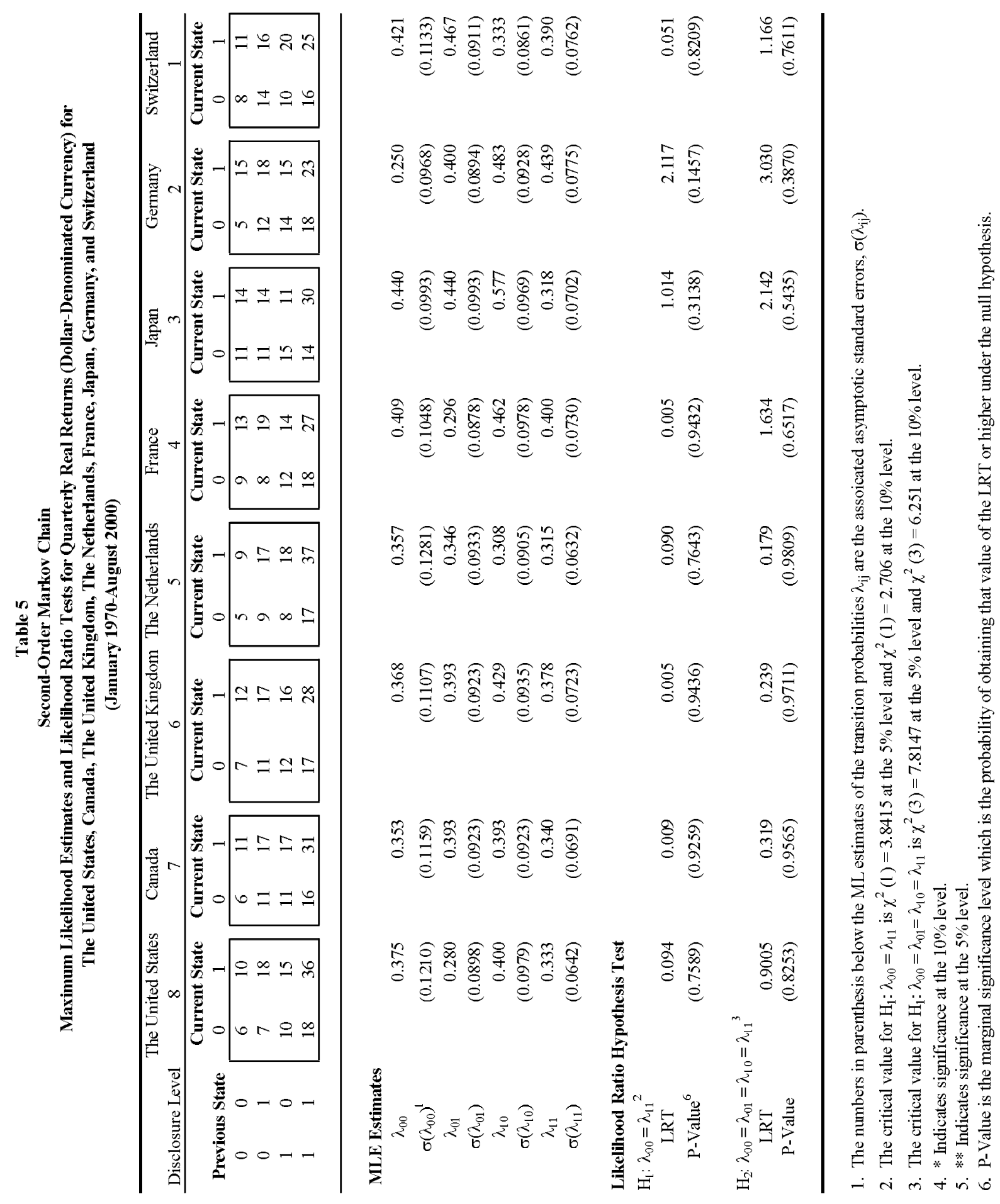




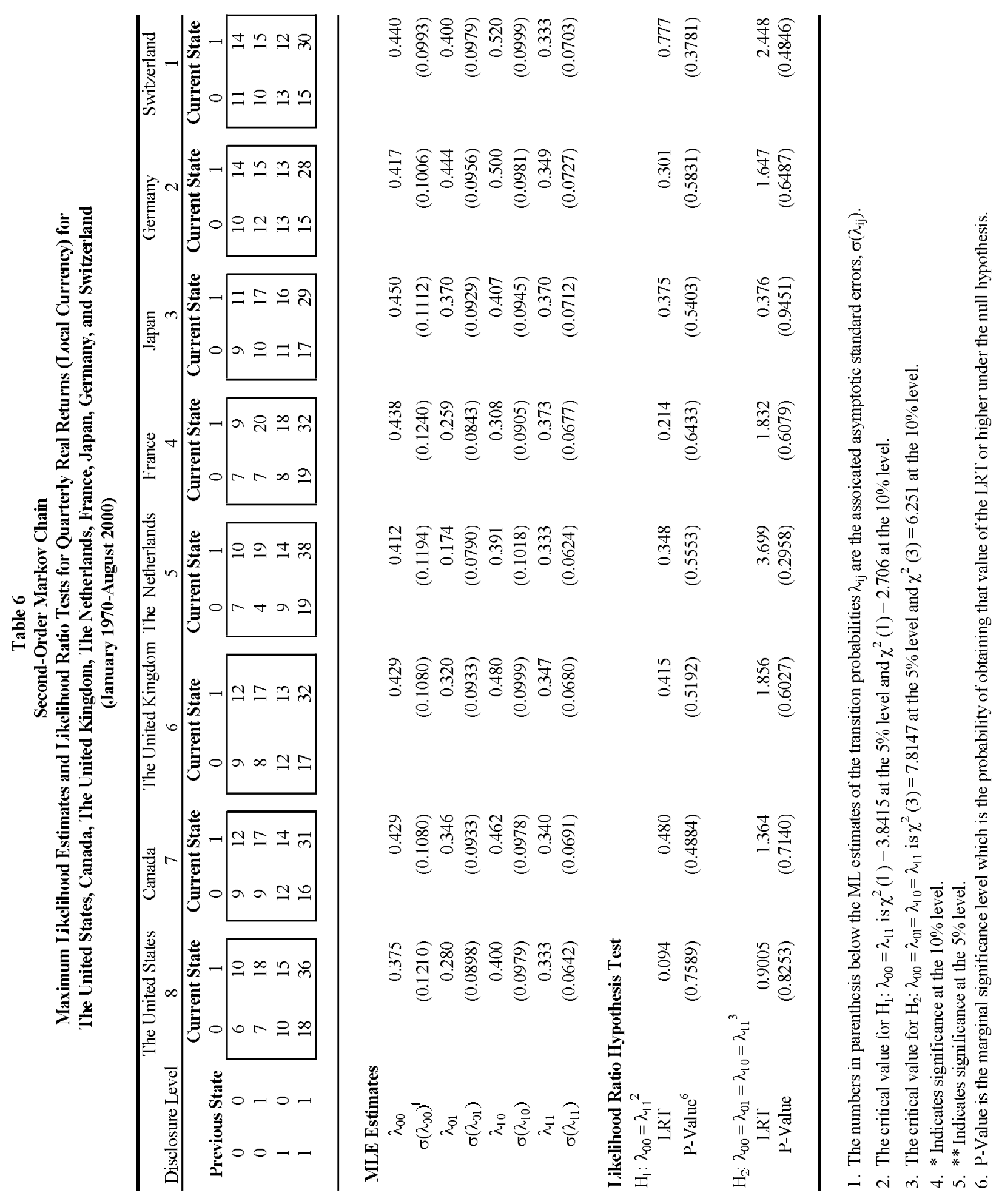




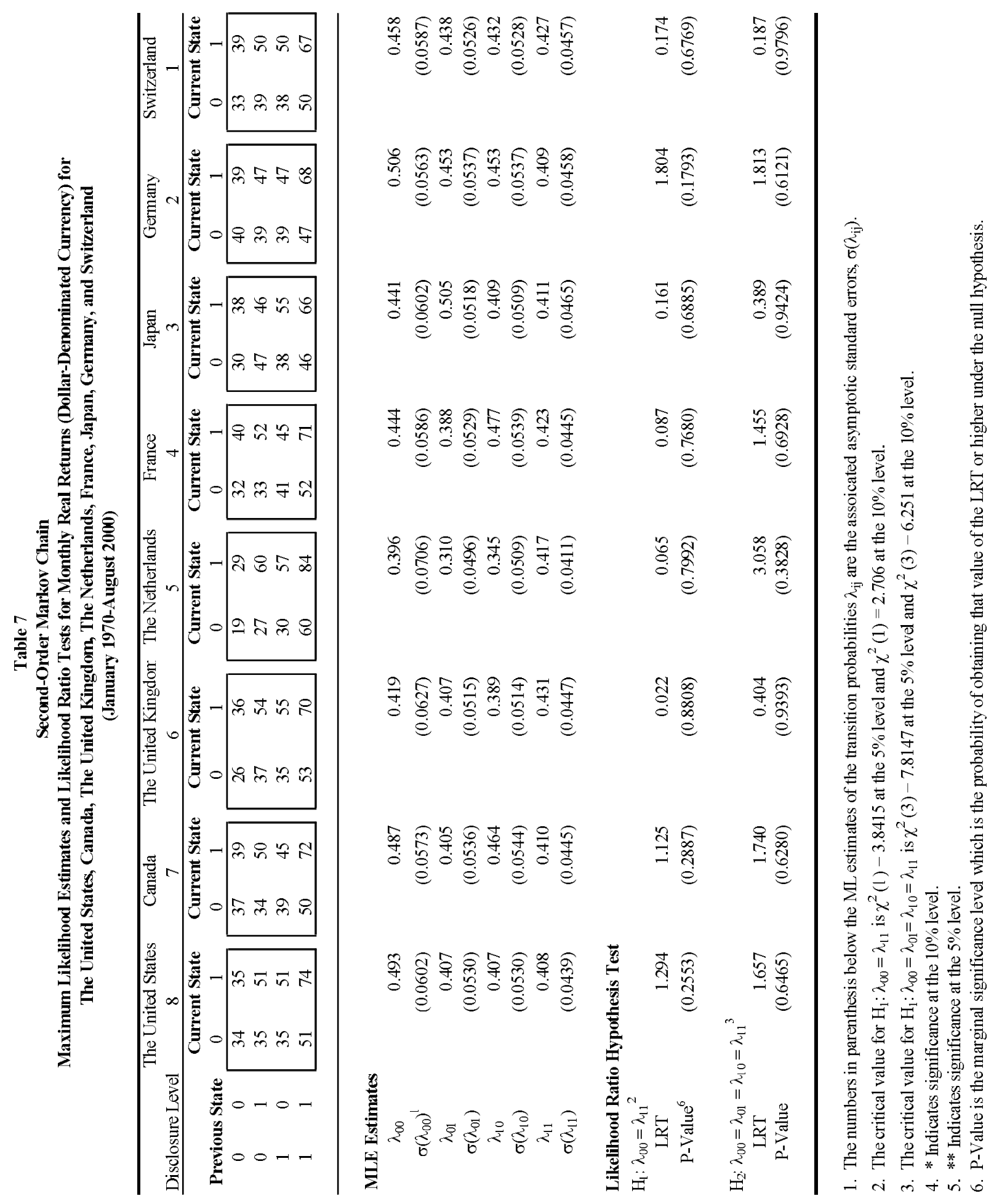




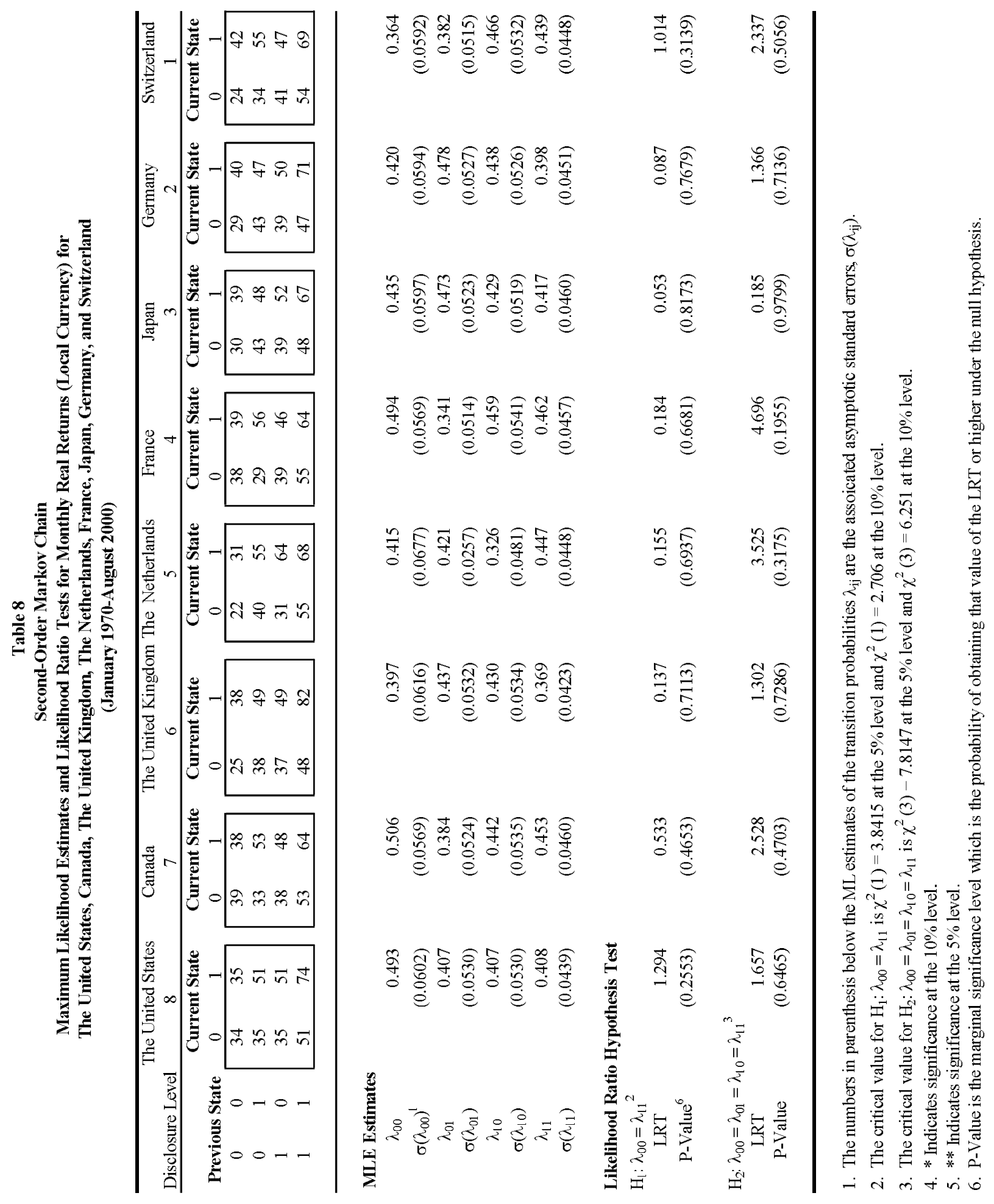




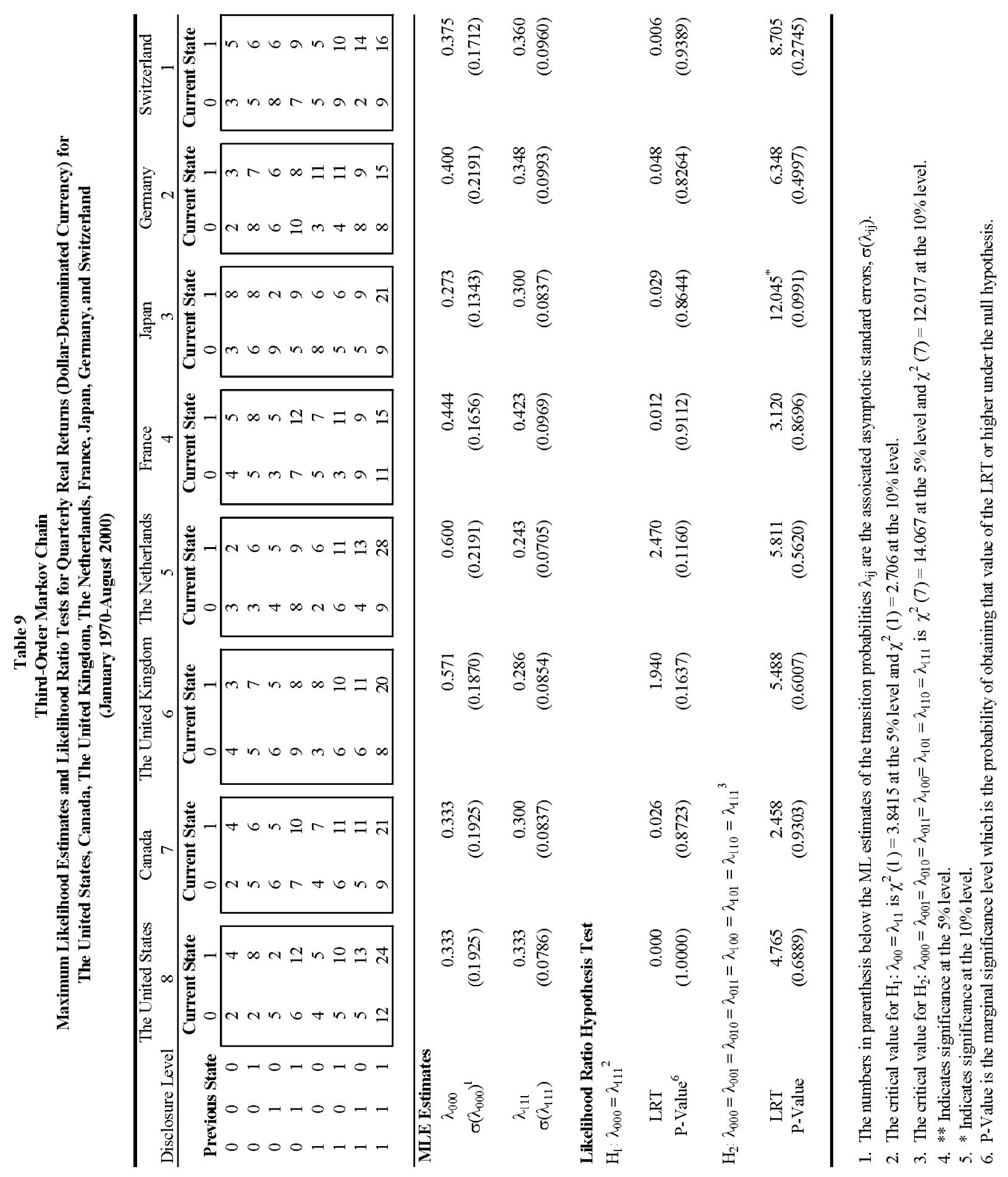




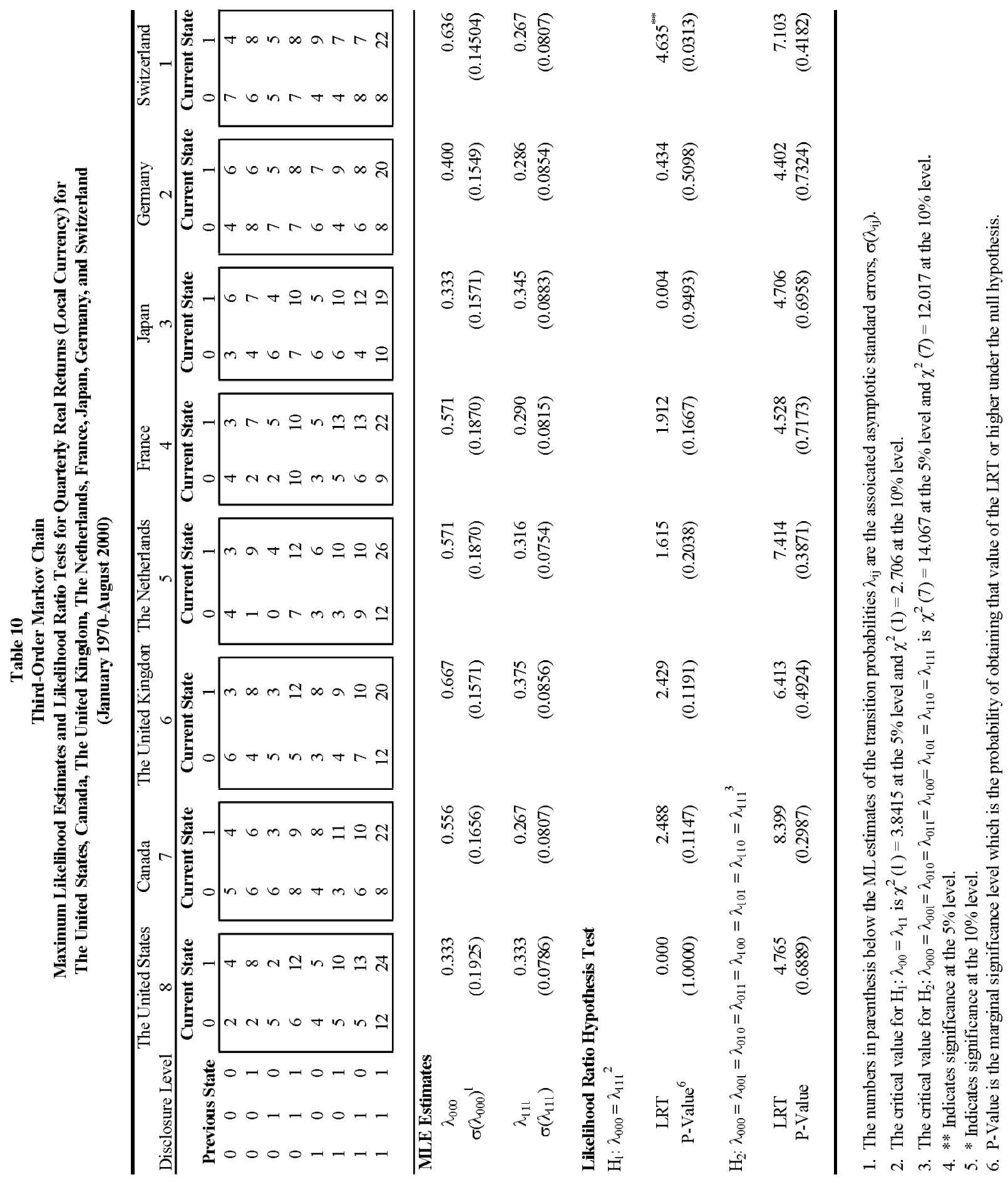




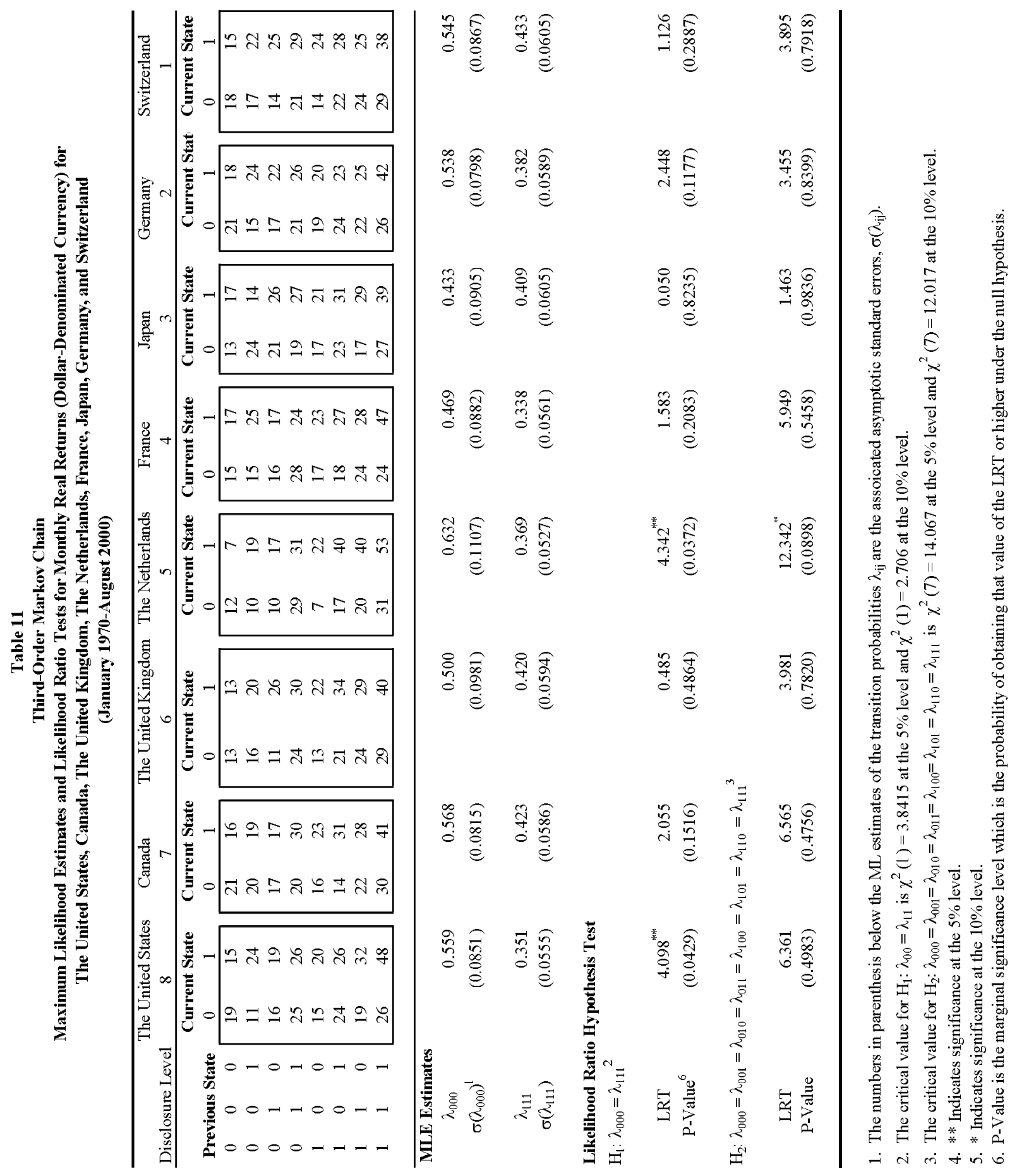




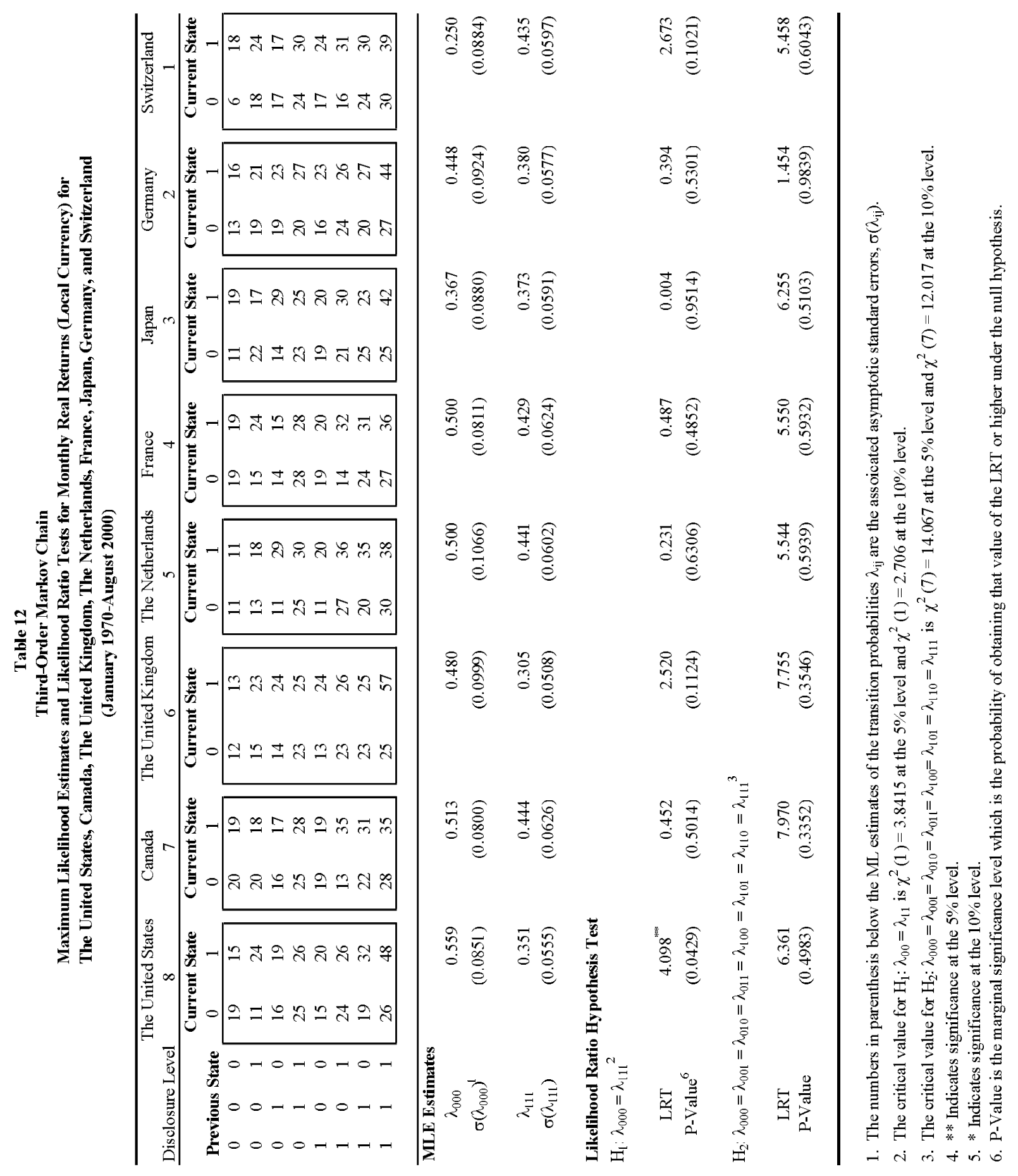




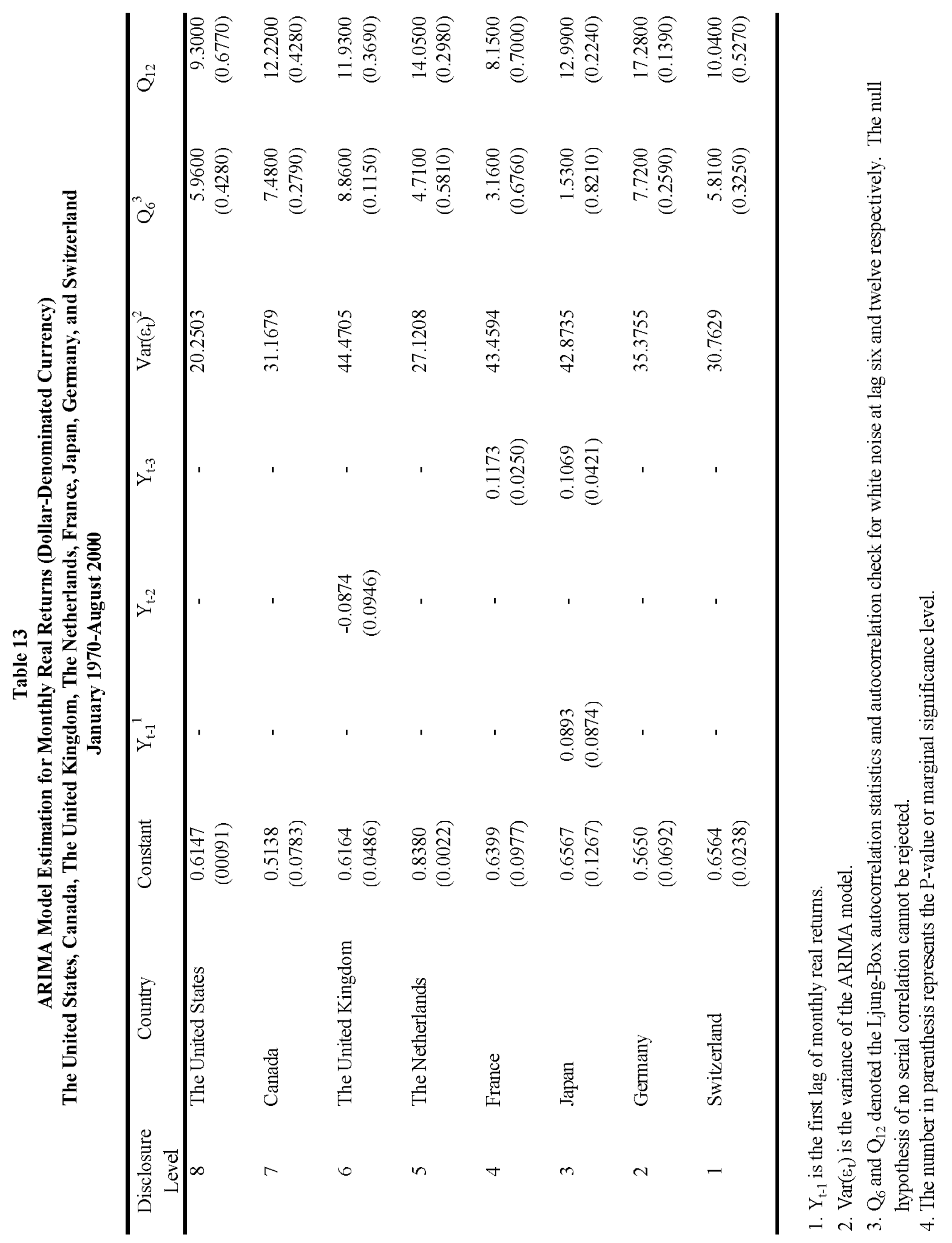




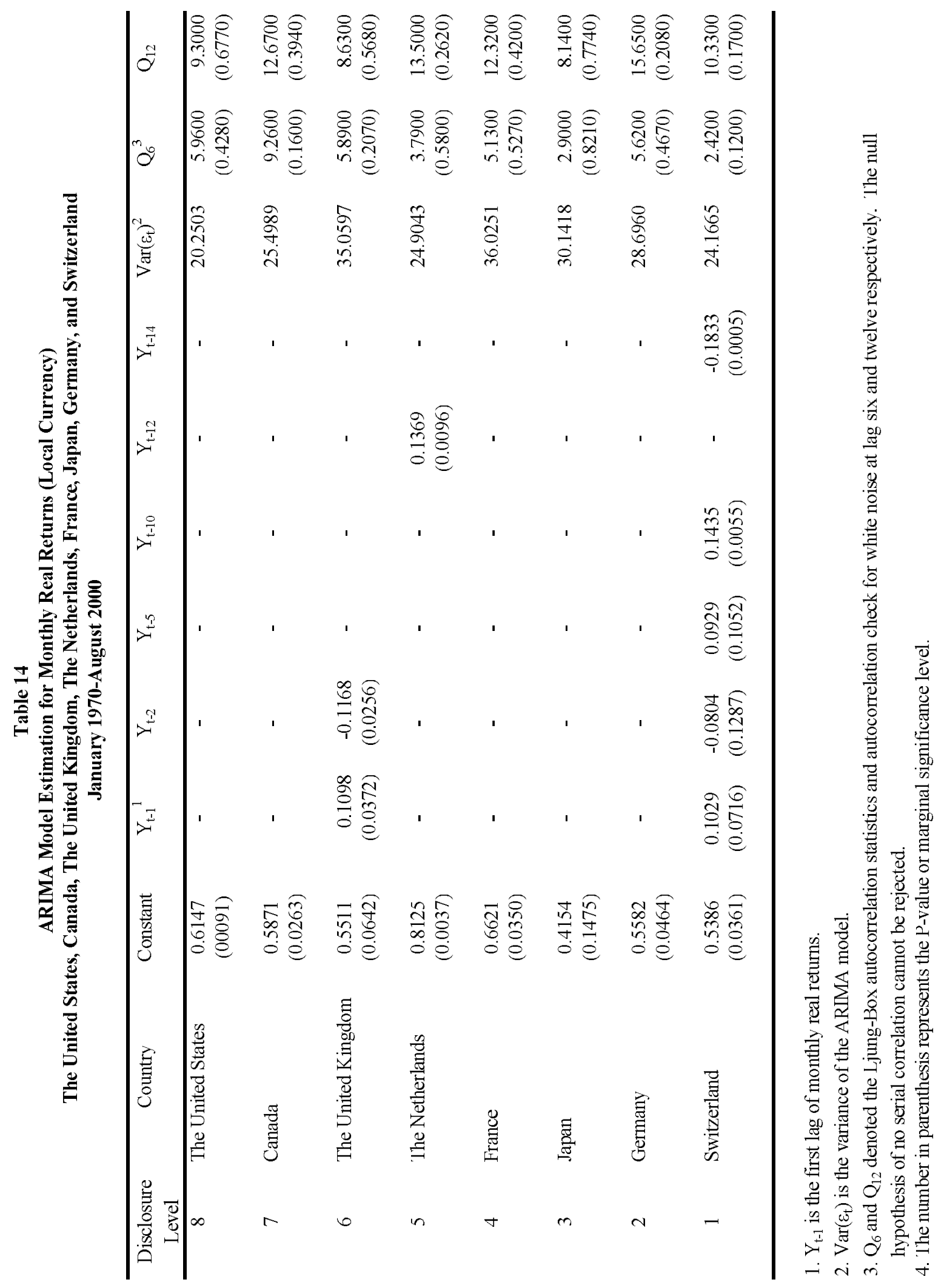




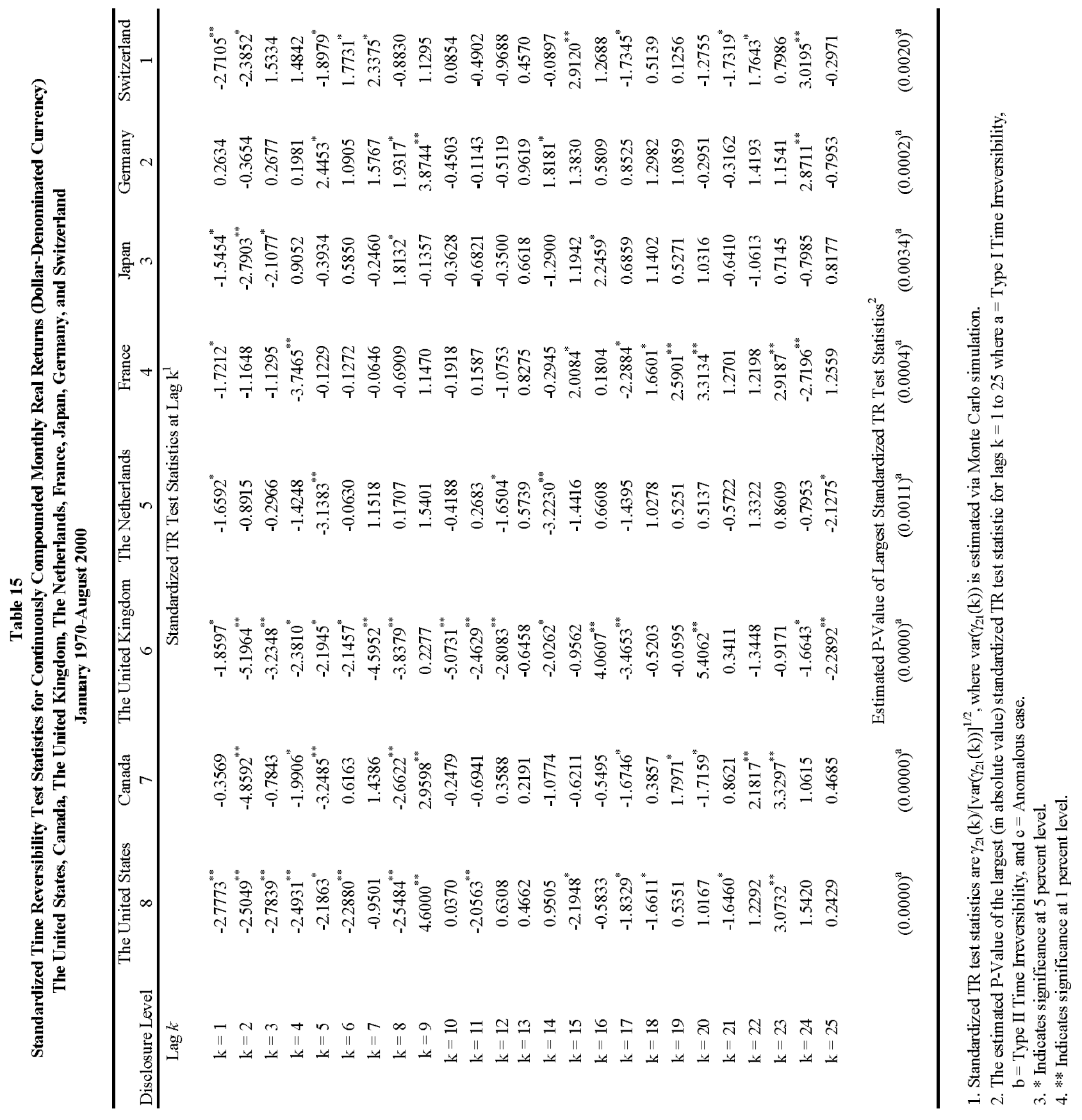




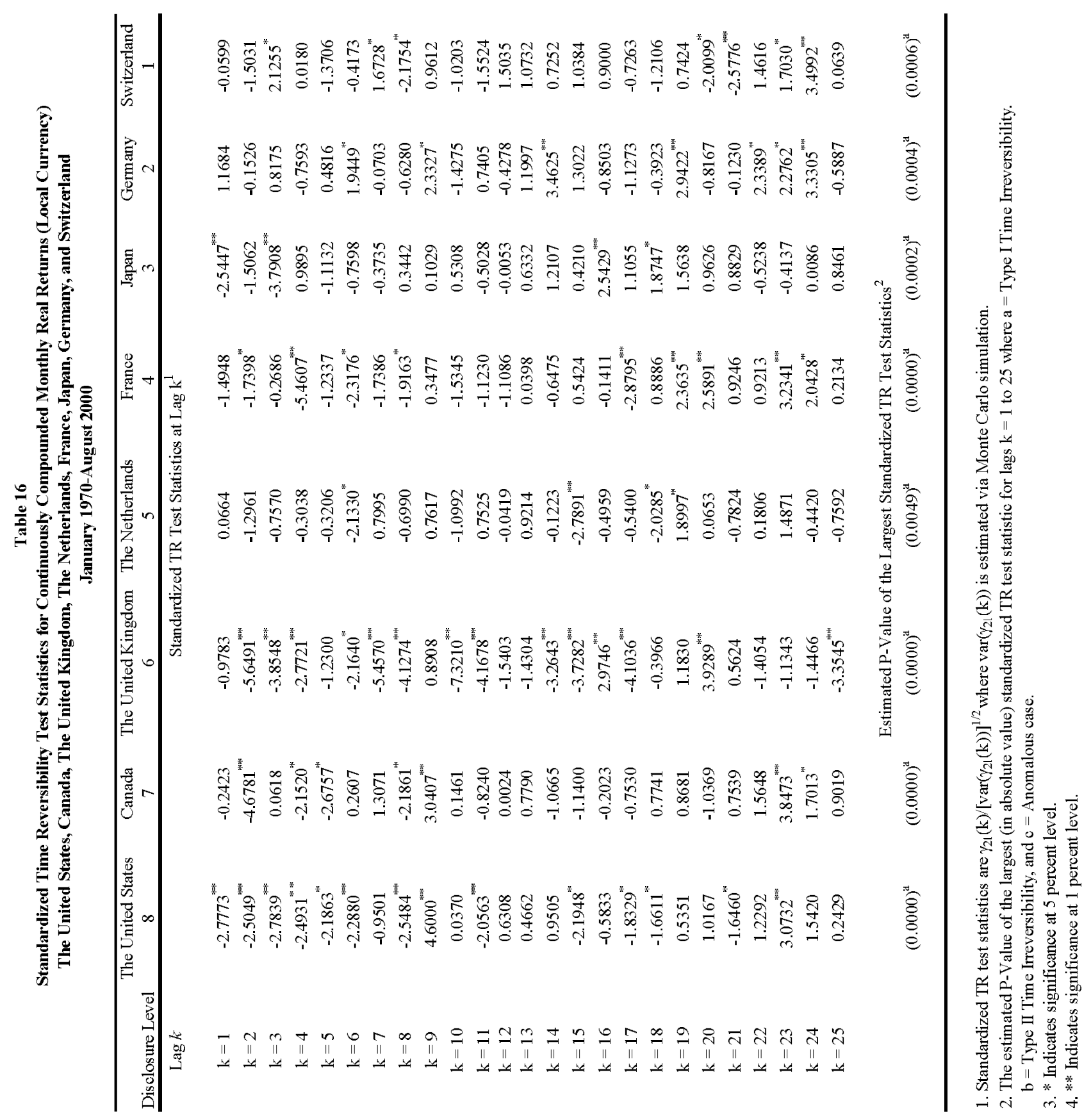




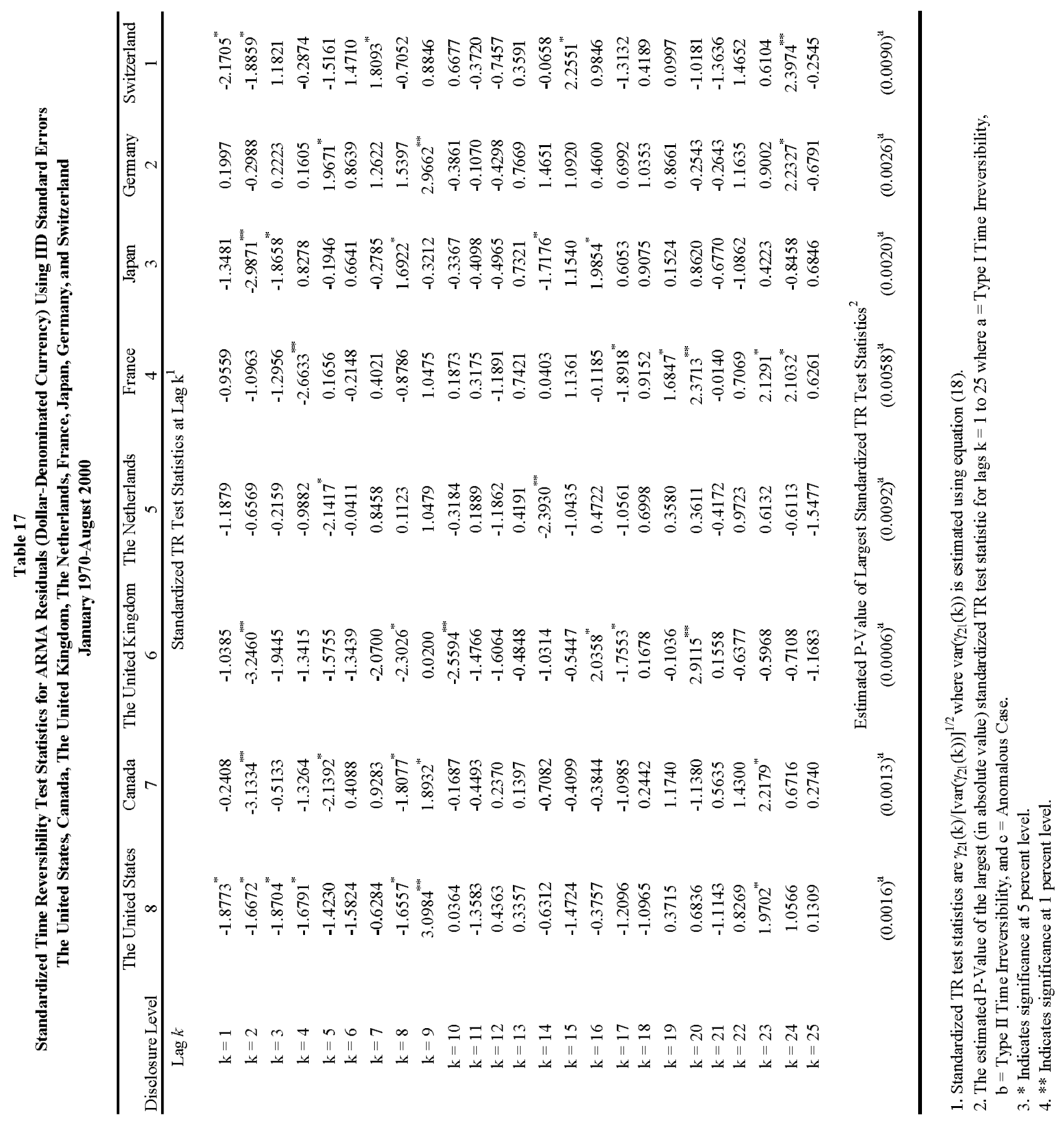




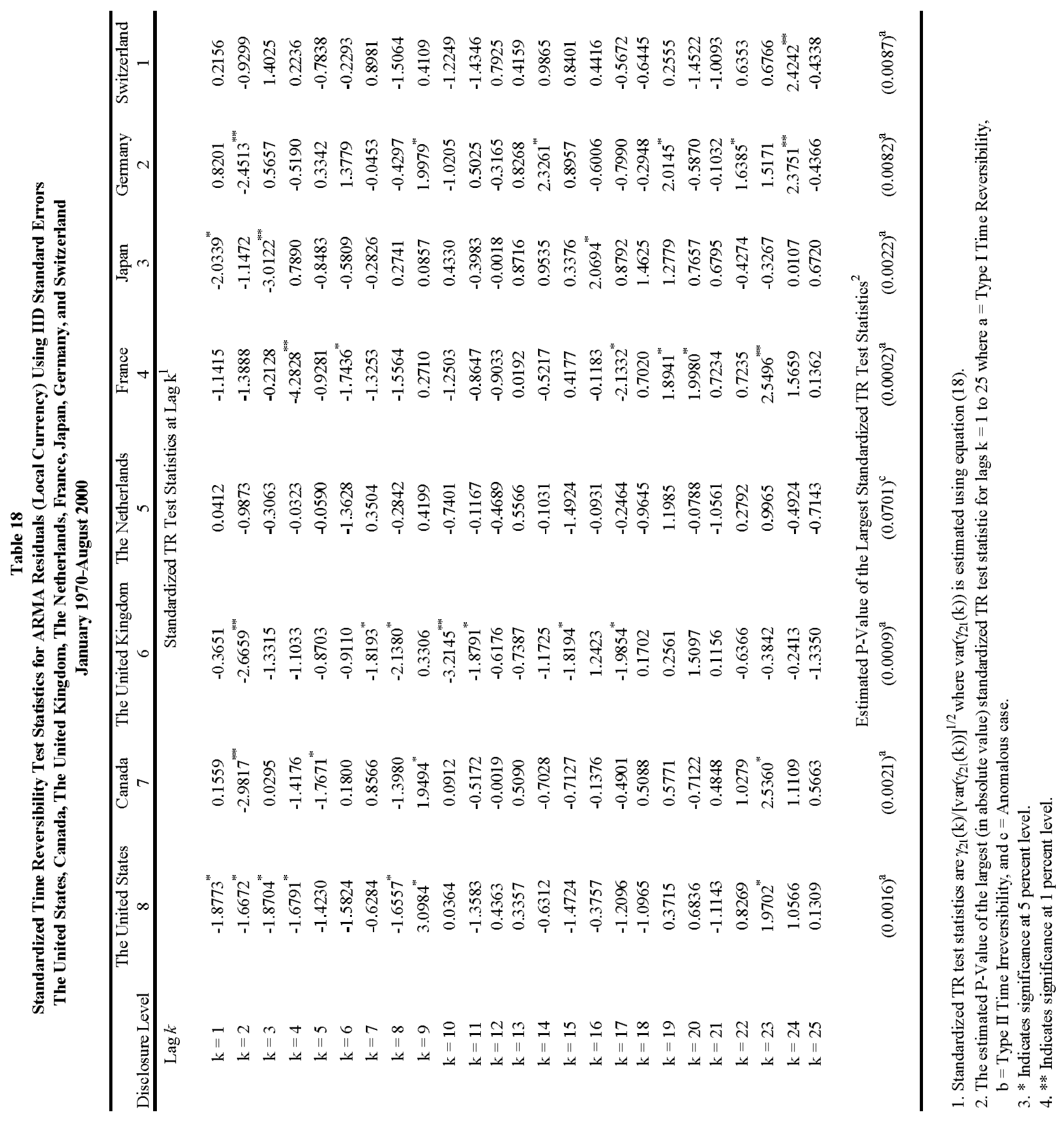


Figure 1: Plots of Estimated TR Test Statistics for Monthly Real Returns vs. Lag k for Eight Countries (Dollar-Denominated Currency)
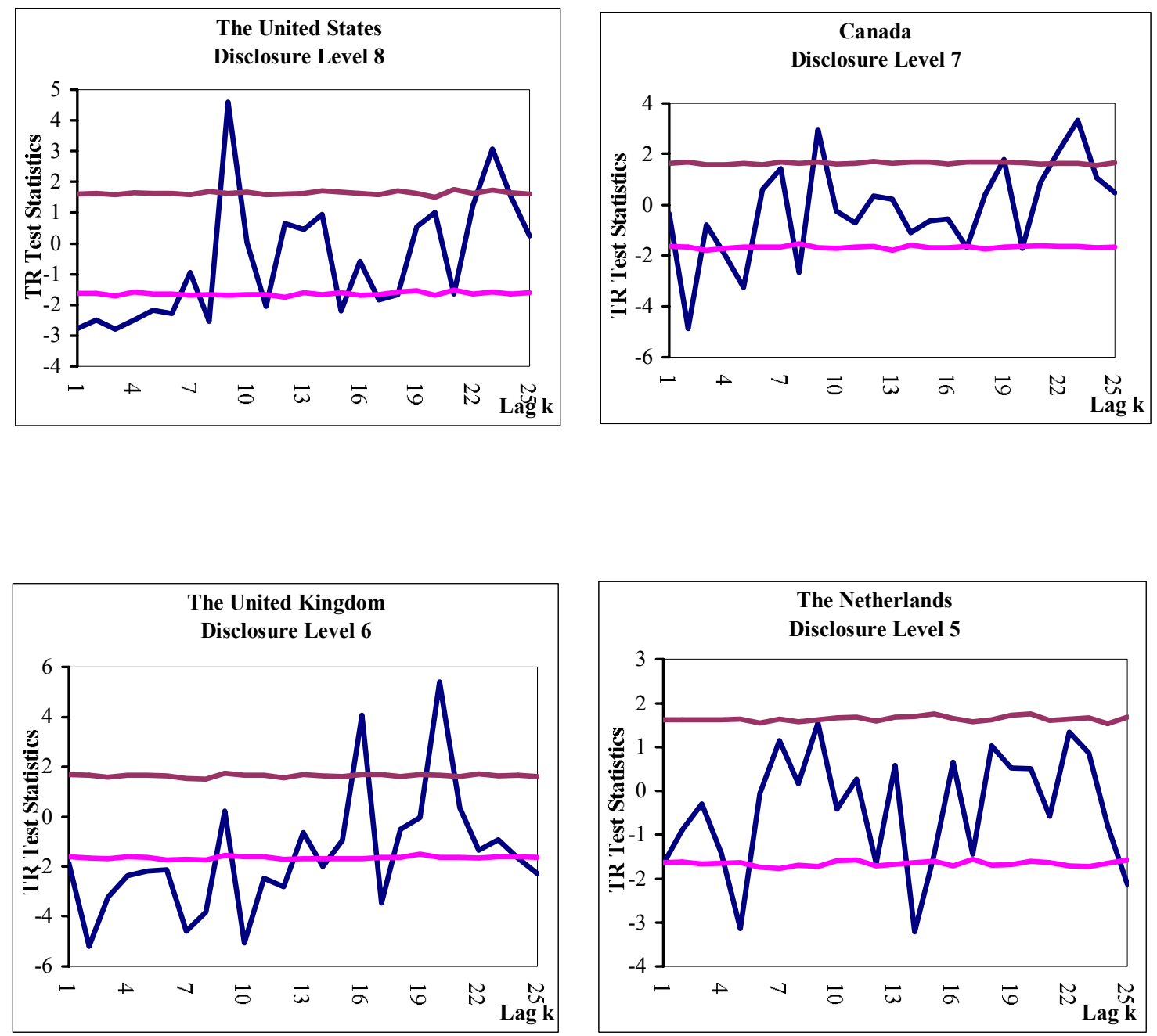

1. The border line at the top and bottom indicates the critical value at 5 percent significance level. The critical value is calculated via Monte Carlo Simulation for each lag $\mathrm{k}$. 
Figure 1: Plot of Estimated TR Test Statistics for Monthly Real Returns vs. Lag k for Eight Countrieis (Dollar-Denominated Currency)
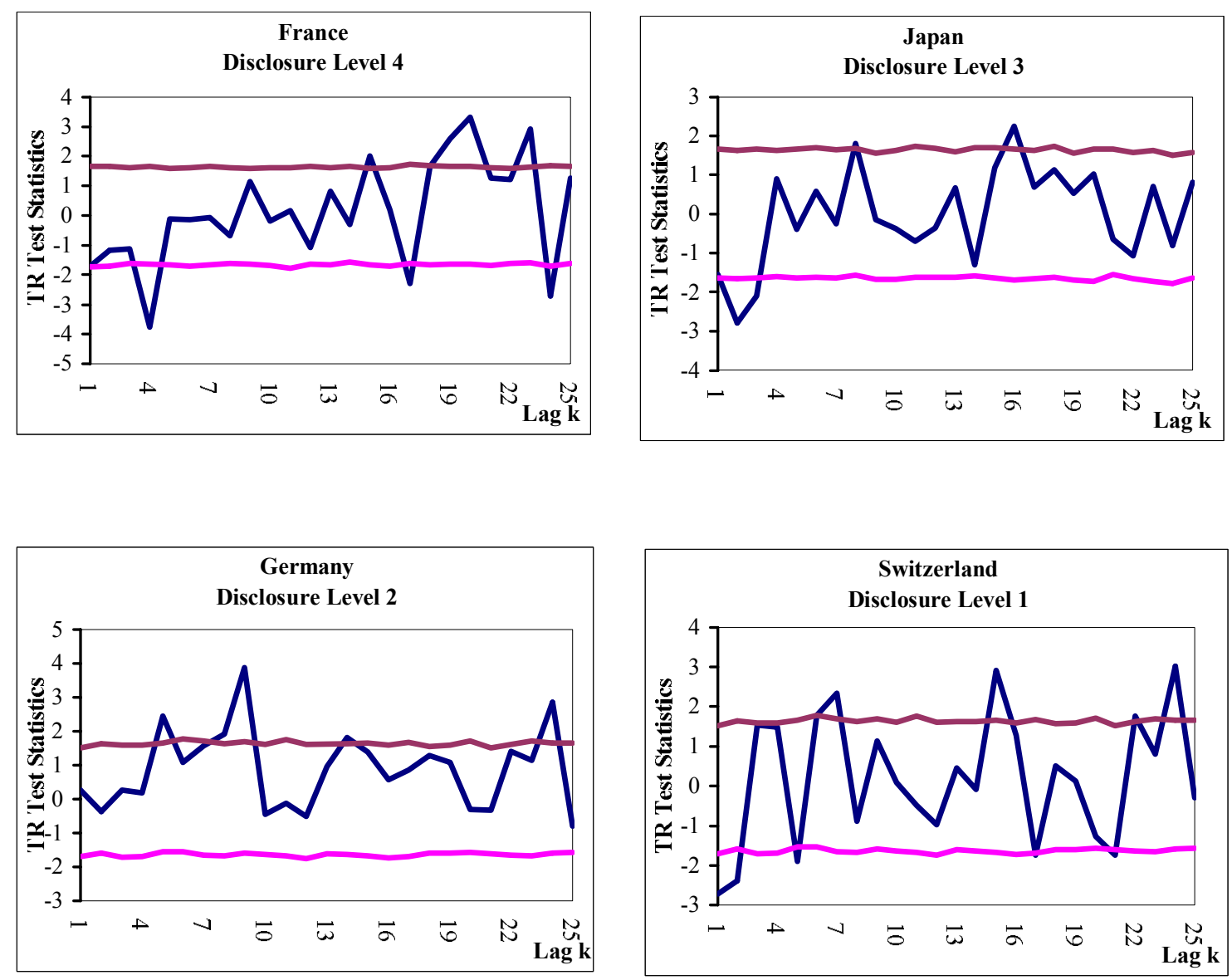

1. The border line at the top and bottom indicates the critical value at 5 percent significance level. The critical value is calculated via Monte Carlo Simulation for each lag $\mathrm{k}$. 
Figure 2: Plot of Estimated TR Test Statistics for Monthly Real Returns vs. Lag k for Eight Countries (Local Currency)
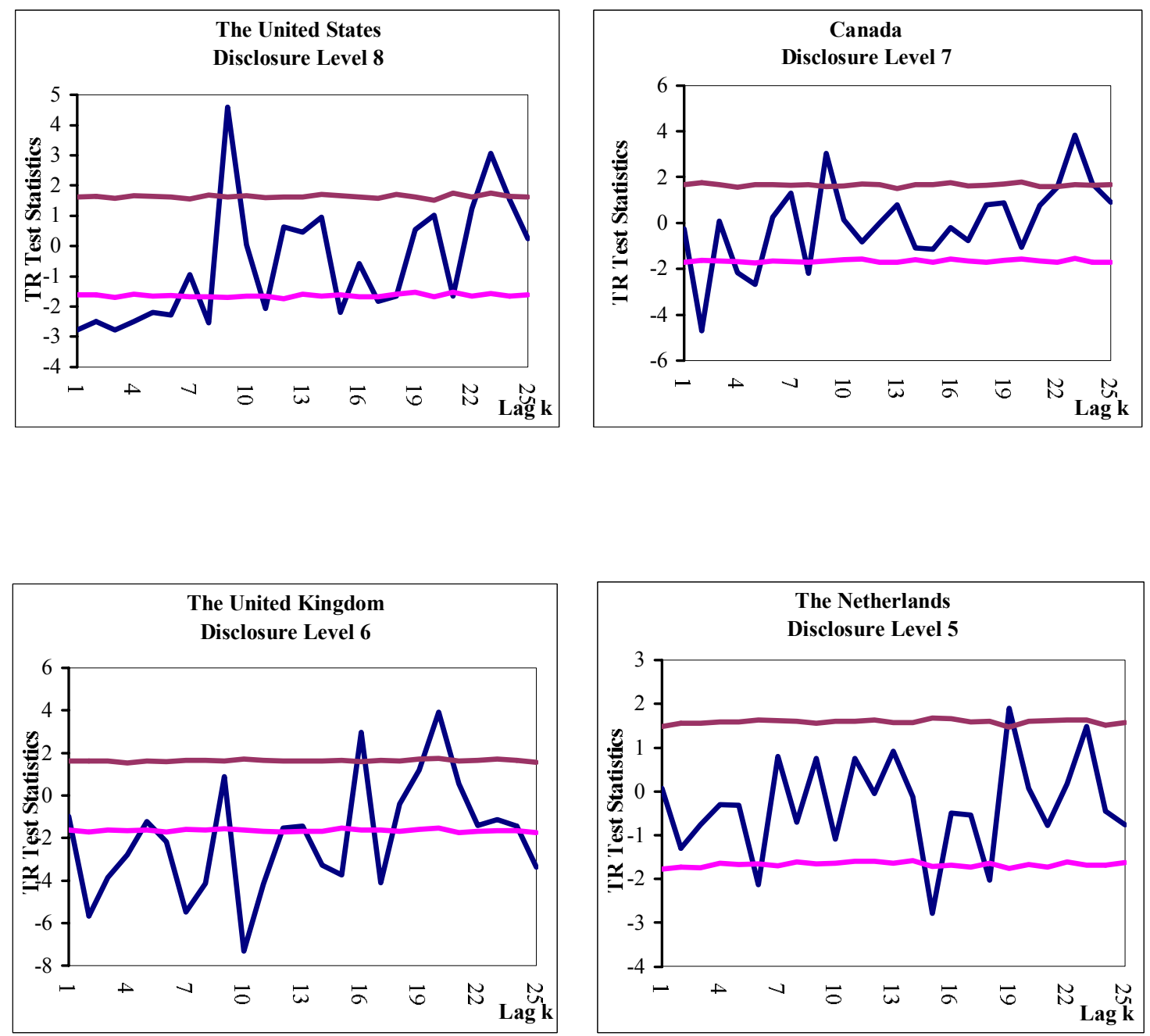

1. The border line at the top and bottom indicates the critical value at 5 percent significance level. The critical value is calculated via Monte Carlo Simulation for each lag $\mathrm{k}$. 
Figure 2: Plots of Estimated TR Test Statistics for Monthly Real Returns vs. Lag k for Eight Countries (Local Currency)
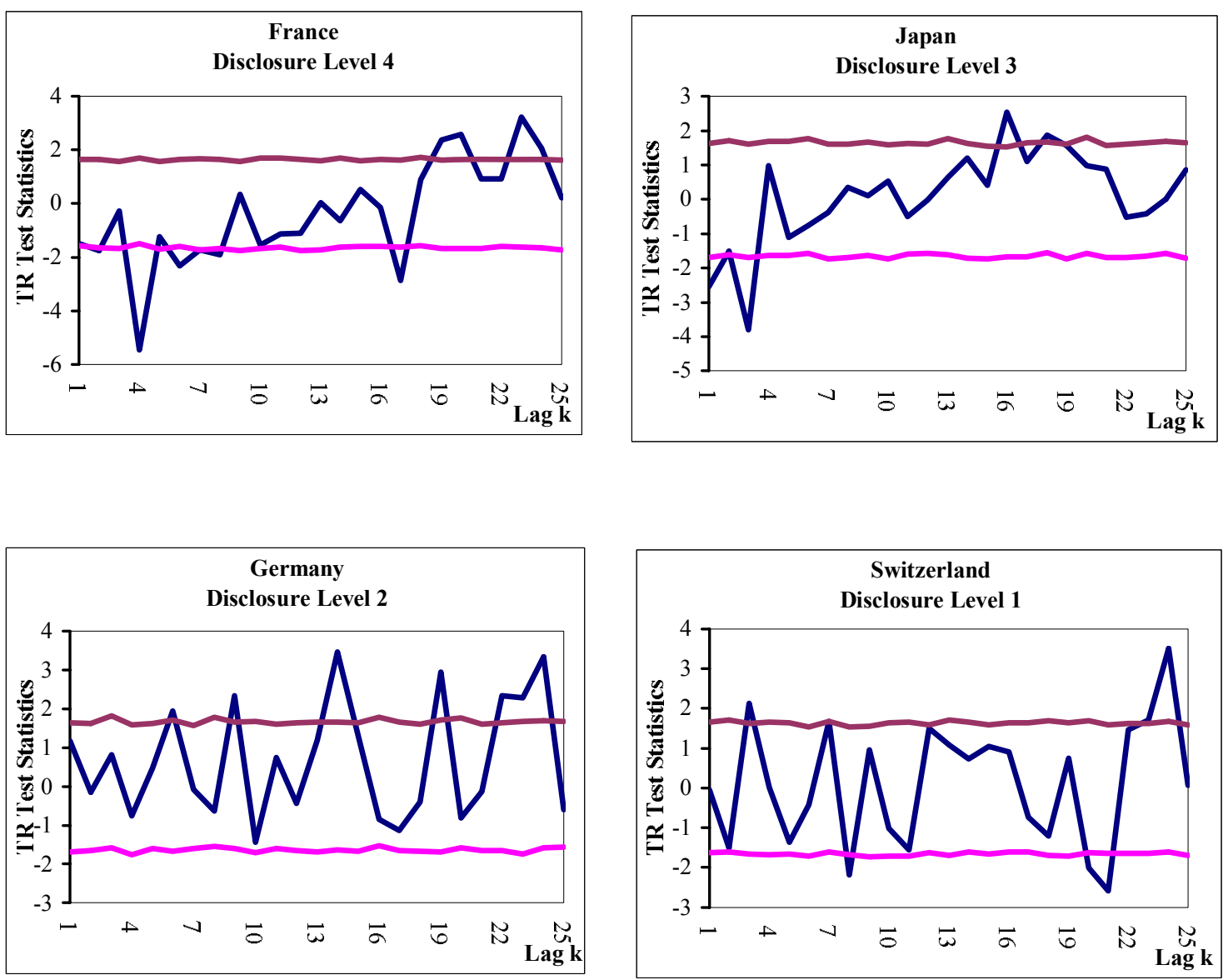

1. The border line at the top and bottom indicates the critical value at 5 percent significance level. The critical value is calculated via Monte Carlo Simulation for each lag k. 
Figure 3: Plots of Estimated TR Test Statistics for the ARMA Residuals of Monthly Real Returns vs. Lag $k$ for Eight Countries

(Dollar-Denominated Currency)
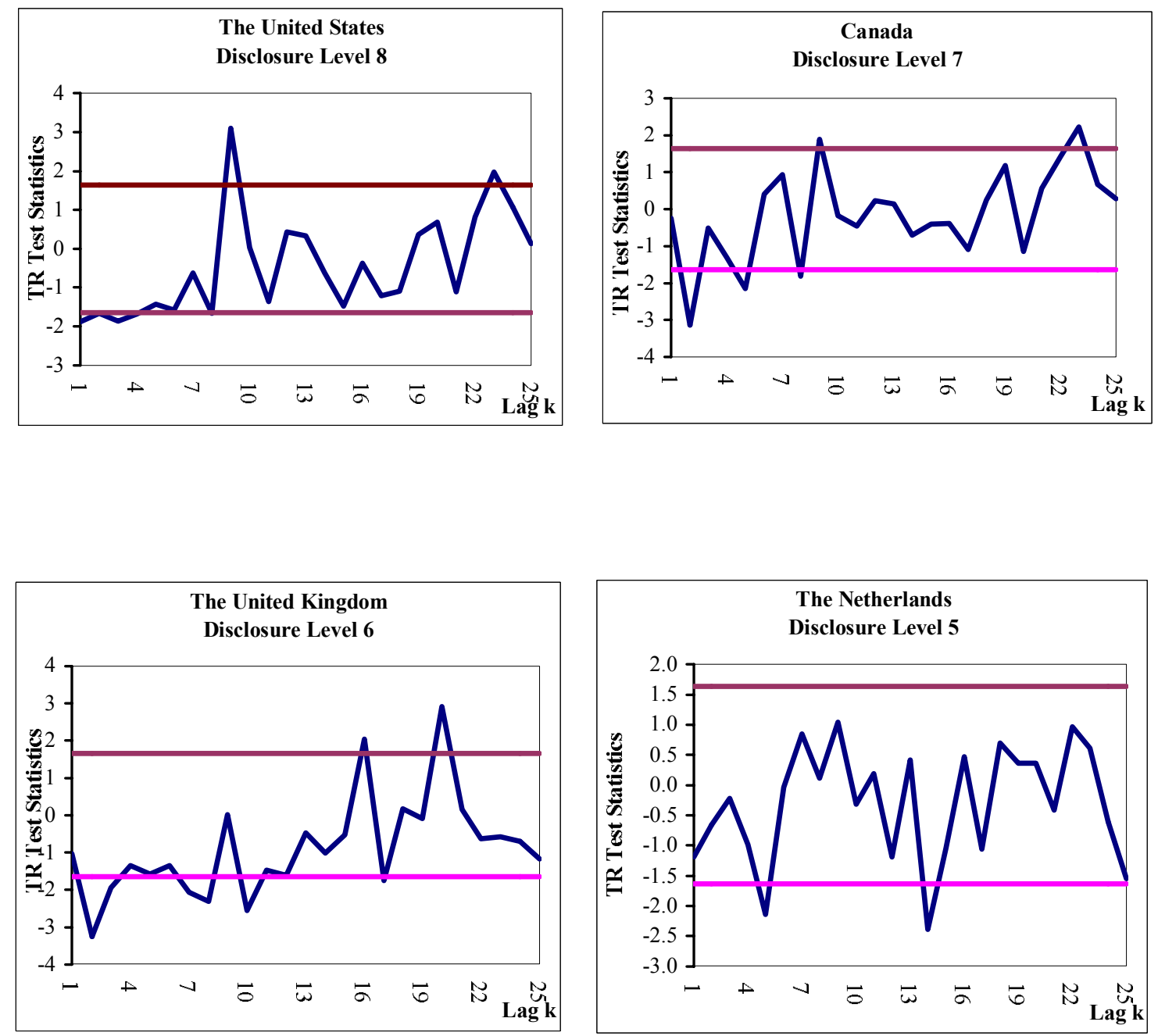

1. The border line at the top and bottom indicates the critical value at 5 percent significance level for one-tailed test. The critical value is obtained fron $\mathrm{N}(0,1)$ distribution. 
Figure 3: Plots of Estimated TR Test Statistics for the ARMA Residuals of Monthly Real Returns vs. Lag $k$ for Eight Countries

(Dollar-Denominated Currency)
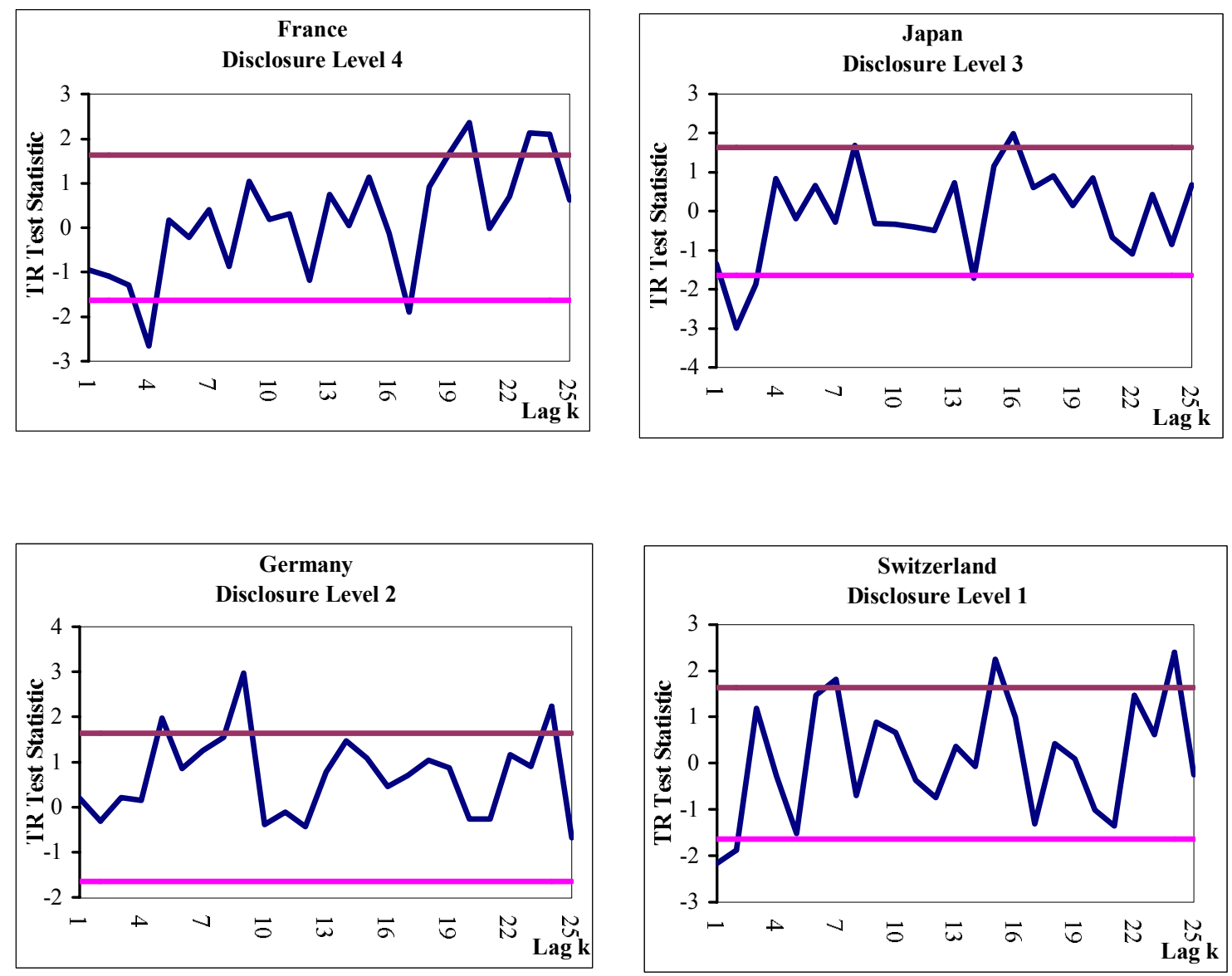

$\overline{1 .}$ The border line at the top and bottom indicates the critical value at 5 percent significance level for one-tailed test. The critical value is obtained from $\mathrm{N}(0,1)$ distribution. 
Figure 4: Plots of Estimated TR Test Statistics for ARMA Residuals of Monthly Real Returns vs. Lag k for Eight Countries (Local Currency)
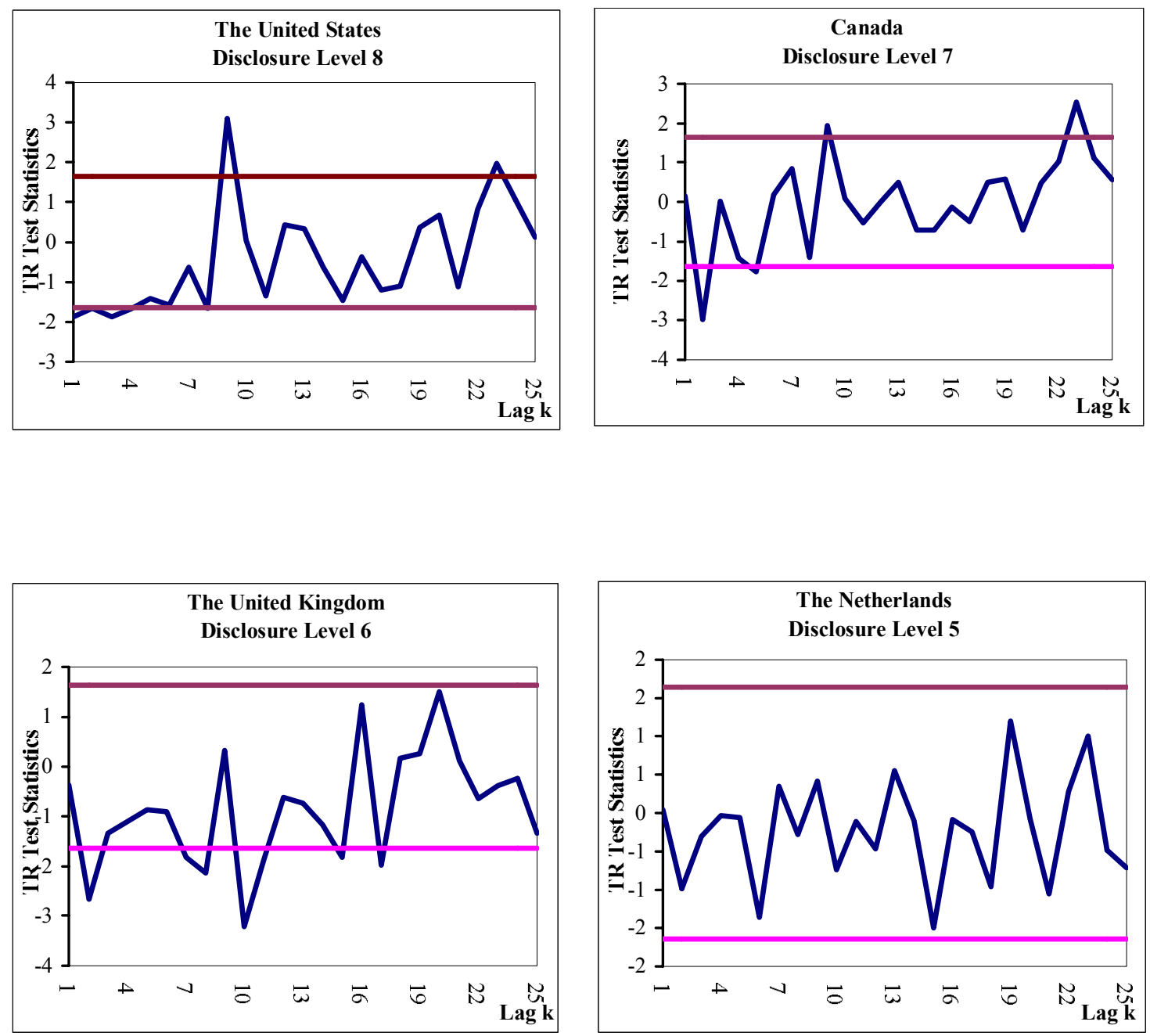

1. The border line at the top and bottom indicates the critical value at 5 percent significance level for one-tailed test. The critical value is obtained from $\mathrm{N}(0,1)$ distribution. 
Figure 4: Plots of Estimated TR Test Statistics for ARMA Residuals of Monthly Real Returns vs. Lag k for Eight Countries (Local Currency)
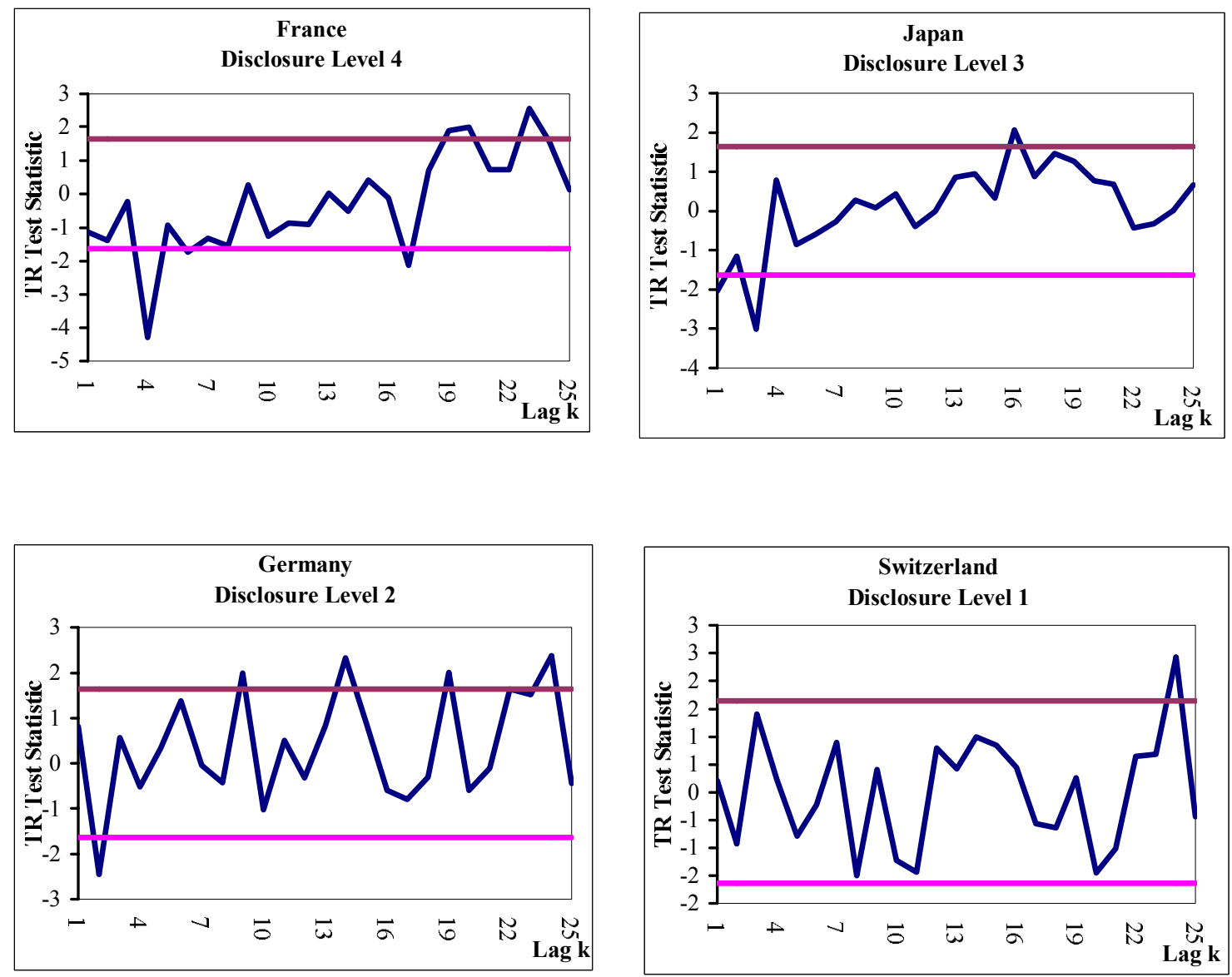

1. The border line at the top and bottom indicates the critical value at 5 percent significance level for one-tailed test. The critical value is obtained from $\mathrm{N}(0,1)$ distribution. 